\title{
LACK OF SPATIAL AND BEHAVIORAL RESPONSES TO IMMUNOCONTRACEPTION APPLICATION IN AFRICAN ELEPHANTS (LOXODONTA AFRICANA)
}

\author{
Audrey K. Delsink, M.Sc., Jay Kirkpatrick, Ph.D., JJ. van Altena, Henk J. Bertschinger, B.VSc., \\ Ph.D., Sam M. Ferreira, Ph.D., and Robert Slotow, Ph.D.
}

\begin{abstract}
Opinions are divided as to whether human intervention to control elephant (Loxodonta africana) population growth is desirable, partly because of elephant welfare concerns. Female contraception through immunization with porcine zona pellucida (PZP) proteins is viable. The effects of sustained use and application of the PZP vaccine on elephant behavioral and spatial responses were examined by evaluating herd ranging, fission-fusion dynamics, association patterns, and reproductive and sexual behaviors. Minimal change was anticipated as a result of long calf dependence on and association with cows, a reduced but not indefinite $0 \%$ growth rate and the known mechanism of action of PZP vaccines, and minimal expected change in resource requirements necessitating behavioral or spatial use adaptations. Although behavioral effects identified in previous hormonal contraceptive trials were evident, it was demonstrated that immunocontraception caused no prolonged behavioral, social, or spatial changes over the 11-yr study period. Individually identified elephants were monitored from 1999 to 2011. Minimal, short-term social disruption, with temporary changes to the herds' core ranges, was observed during the annual treatment events, particularly in the first three treatment years, when vaccinations were conducted exclusively from the ground. Thereafter, when vaccinations were conducted aerially, minor disruptions were confined to the morning of administration only. Despite sustained treatments resulting in demographic changes of fewer calves being born, treatments did not alter spatial range use, and no adverse interherd-intraherd relations were observed. Similarly, resource requirements did not change as calving still occurred, although in fewer numbers. It was concluded that PZP immunocontraception has no detectable behavioral or social consequences in elephants over the course of 11 yr, providing a convincing argument for the use of sustained immunocontraception in the medium to long term as an important tool for elephant management. Behavioral consequences of alternative management approaches should all receive similar scrutiny to enable managers to make informed decisions when weighing management interventions.
\end{abstract}

Key words: African elephant, behavior, immunocontraception, Loxodonta africana, management, population control.

\section{INTRODUCTION}

Large mammals affect ecosystems and in some instances may be key drivers of processes. . $3,70,100^{2}$ When constraints imposed by humans remove spatial and temporal regulating mechanisms, management challenges are accentuated. ${ }^{3,6,50,90}$ Keystone mammals may then have undesirable

From the Amarula Elephant Research Programme, School of Life Sciences, University of KwaZulu-Natal, Westville Campus, Private Bag 54001, Durban, 4040, Republic of South Africa (Delsink, Slotow); the Science and Conservation Center, 2100 S. Shiloh Drive, Billings, Montana 59106, USA (Kirkpatrick); Global Supplies, Highlands North, Gauteng, 2037, Republic of South Africa (van Altena); the University of Pretoria, Section of Reproduction, Private Bag X04, Onderstepoort, Tshwane, 0110, Republic of South Africa (Bertschinger); and South African National Parks, P.O. Box 202, Skukuza, Mpumulanga, 1353, Republic of South Africa (Ferreira). Correspondence should be directed to Ms. Delsink (auds@radioactivewifi.co.za). consequences on biological, ${ }^{68-70}$ economic, ${ }^{14,67,81}$ or other human values. ${ }^{9}$ In such cases, conservationists intervene to minimize the undesirable effects of large mammals, ${ }^{69}$ in particular those of megaherbivores. ${ }^{22,28,53,75}$

African elephants (Loxodonta africana) epitomize the challenges that conservationists face when attempting to mitigate the influences of mega-herbivores. Elephants conflict with human livelihoods, ${ }^{60,81,86,101}$ change woodlands to shrublands, ${ }^{39}$ and mechanically transmit diseases, ${ }^{83}$ but they also enhance tourist revenue. ${ }^{78,91}$ They are also persecuted illegally $y^{25,39,92}$ and exploited legally. ${ }^{19,37}$ Generally, though, conservationists argue based on ecological reasons when attempting to manage the effects of elephants (i.e., the ability of elephants to influence biodiversity through changes to species composition, vegetation structure, and functioning of the ecosystem by virtue of their feeding habits). ${ }^{16,39}$ However, nonconsumptive, sustainable-use approaches practiced by many South African 
reserves focus on tourism products as a valid land-use option (e.g., privately owned white rhinos offer primarily financial objectives, over and above their conservation contribution, and comprised $24.1 \%$ of all white rhinos (Certotherium simun) in South Africa during 2010) ${ }^{46}$ In small to medium-sized reserves $\left(<1,000 \mathrm{~km}^{2}\right)$, and even historically in large reserves, such as Kruger National Park (KNP), tourist viewing potential is maximized through the increase in road infrastructure and artificial waterholes. ${ }^{76,77}$ Such resource manipulation coupled with an enclosed (fenced-in) status exacerbate the "elephant density effect" (i.e., the consequences that depend on the local abundance of elephants, as they breed faster ${ }^{52}$ and have smaller home ranges ${ }^{87}$ within these reserves), and the intensity with which they use landscapes increases and homogenizes. ${ }^{88,89}$

This elephant density effect necessitates management of elephant abundance and spatial use to reduce undesirable ecological effects. ${ }^{39}$ Elephant management options to address these factors are outlined in South Africa's Norms and Standards for Elephant Management. ${ }^{19}$ Among these options is immunocontraception, which manipulates elephant densities in the medium term. ${ }^{21,22,28}$ To address negative elephant density effects, immunocontraception must reduce abundances or maintain them at acceptable levels. Outcomes are most effective when complimentary management induces variable elephant use of landscapes. In addition, adverse behavioral effects as a result of immunocontraception are undesirable from a welfare $e^{4,43,45}$ as well as an ecologic ${ }^{40,59}$ perspective.

Early attempts at contraception used hormonal implants. The long-lasting estrogen implants, inserted subcutaneously during the estradiol trials, in free-roaming elephants in the KNP induced prolonged states of sexual attractiveness, with treated cows being subject to continual male harassment, which disturbed family groups and endangered young calves. ${ }^{95}$ This generated concern among scientists and the public alike, ${ }^{79}$ and the application of hormone implants was discontinued. ${ }^{94}$

An alternative contraceptive approach is immunization with porcine zona pellucida (PZP) glycoproteins prepared from pig ovaries. ${ }^{21} \mathrm{PZP}$ immunocontraception is effective, reversible, remotely deliverable, and lacks physiological side effects in horses (Equus caballus). ${ }^{42,51}$ For elephants, the immunocontraceptive trials in KNP (run in conjunction with estradiol trials, hence the confusion between the two methodologies) demonstrated that PZP vaccination was effective, ${ }^{32}$ and no short-term effects on the sexual or social behavior of the elephants were seen. ${ }^{94}$ Similarly, immunocontraception in the Munyawana Conservancy in South Africa's KwaZulu-Natal demonstrated no effects on sexual, social, or ranging behavior of elephants during the 4.5-yr study. ${ }^{27}$ However, it is speculated $^{40,94}$ that PZP immunocontraception could potentially have short- to medium-term adverse behavioral consequences because females cycle more often, as they are not conceiving, and thus should receive more attention from musth bulls. This predicts that the association of musth bulls with females should increase over time, as the incidence of estrus events increases after contraception. In addition, the effects of no or fewer infants and calves on female aggression are unknown and are potentially of concern. ${ }^{40}$ Together with increased male attention, it is predicted that females may become more aggressive over time, possibly in relation to humans and elephants alike, as a result of the association of musth bulls or increased bull presence and reduction in dependent calves in a breeding group.

On a longer timescale, a breeding herd's resource needs may change because the herd has fewer suckling calves and pregnant females and a reduced number of juveniles. This predicts a change in a breeding group's spatial use of landscapes ${ }^{40}$ and, thus, a change in their ranging behavior. Such change in spatial behavior could mitigate or exacerbate existing elephant effects through a shift in range use. It is not expected that a significant spatial shift due to resource need changes, by individuals or the herd, will occur as the herd will still act as a cohesive unit, and there will still be pregnant and lactating cows and infant calves, although in fewer numbers.

This study tests these predictions following the sustained PZP immunocontraception of four breeding herds studied in a medium-size reserve in South Africa. First, the disturbance effect of treatments through a spatial response was assessed. Second, whether range use changed in the medium term for these four breeding groups was assessed. Lastly, behavioral observations to measure social and reproductive interactions to evaluate behavioral predictions were used. The focus was on following the responses of four breeding herds over a period of $11 \mathrm{yr}$ to reflect on medium-term responses to PZP immunocontraception treatment. It was hypothesized that 


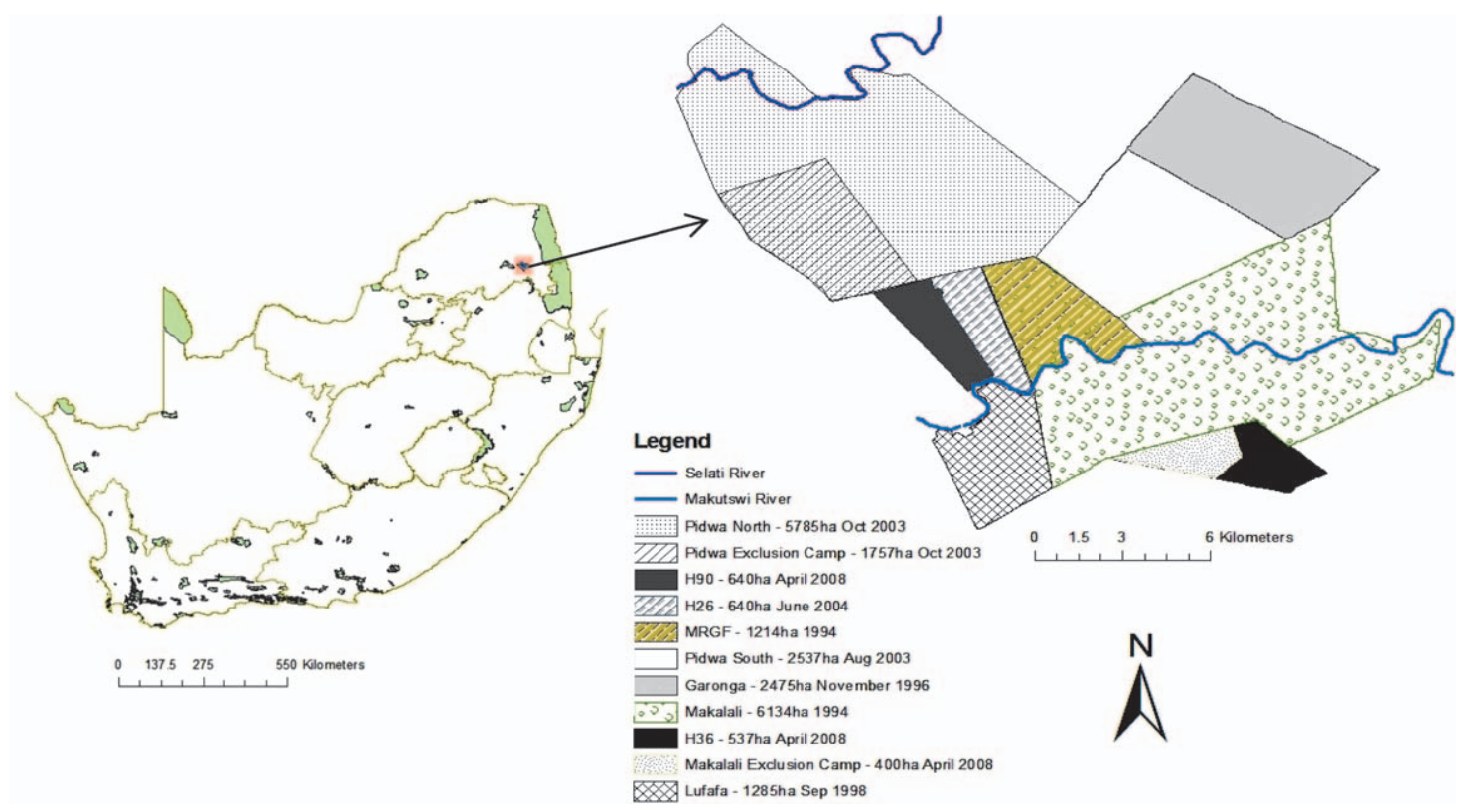

Figure 1. The Greater Makalali Private Game Reserve; individual properties, sizes, and dates of incorporation into the larger reserve. (SA map: http://bgis.sanbi.org/vegmap/map.asp)

immunocontraception causes no adverse behavioral or social impacts with sustained use in the medium term.

\section{MATERIALS AND METHODS}

\section{Study area}

The Greater Makalali Private Game Reserve (GMPGR) is located in the foothills of the Drakensberg Mountains in South Africa's Limpopo Province $\left(30.49^{\circ} \mathrm{S} ; 24.00^{\circ} \mathrm{E}\right)$. From March 1999 to April 2008, the reserve's contiguous open system (Makalali, Garonga, Makhutswi River Game Farms and Lufafa) increased from 111 $\mathrm{km}^{2}$-with the addition of $25 \mathrm{~km}^{2}$ in August 2000 (Pidwa South), $58 \mathrm{~km}^{2}$ in October 2003 (Pidwa North), $7 \mathrm{~km}^{2}$ in June 2004 (Natural Echo), and $12 \mathrm{~km}^{2}$ in April 2008 (Kgoro and Kristi's) - to a total size of $213 \mathrm{~km}^{2}$ (Fig. 1). The main vegetation type is Combretum apiculatum veld of Mixed Bushveld. ${ }^{1}$ Situated on the Lowveld plain at altitudes of $300-500 \mathrm{~m}$ above sea level, the GMPGR is bisected by $\pm 21 \mathrm{~km}$ of the perennial Makhutswi River in the south (it bisects Makalali, is the southern boundary for H90 and H26 and the northern boundary for Lufafa) and $\pm 8.5 \mathrm{~km}$ of the seasonal Selati River in the north. The GMPGR is situated in a summer rainfall area with a mean annual rainfall of $450 \mathrm{~mm}$.

\section{Elephant population}

Each elephant is known and can be recognized according to previously described methods. ${ }^{55,65,93}$ All of the elephants have complete identification kits comprising frontal, left-, and right-sketched ear templates with corresponding photographs. ${ }^{20,24}$ The animals were sexed and aged following the methodology of Moss and Poole ${ }^{55,65}$ using head shape, known ages, rough estimates based on general appearance, shoulder height, and age correlation and general categorization.

A total of four elephant herds, comprising intact family units with established matriarchs, were reintroduced to the GMPGR from the KNP in 1994 (units of eight and five animals were captured from the same area on 12 May 1994) and supplemented in 1996 (units of 12 and 13 animals captured from areas referred to as 'Jones se Dam' and "Riet Pan" on 29 May 1996 and 31 May 1996, respectively) (Malan, pers. comm.). The herds are referred to by the matriarch name (i.e., Holey Ear, Kwatile, Yvonne, and Queeny). Together, these four core herds make up the Makalali clan. An additional five adult males entered the reserve in 2000 and 2001, two more in September 2005, and one more in January 2006, breaking in through the electrified boundary fence. During the 20012008 period, six of these bulls were removed as part of the management strategy, and two natural 
mortalities were recorded. As PZP does not affect pregnancies in progress, population growth was noted until $100 \%$ reproductive control (when all pregnant females at primary vaccine administration have calved and the vaccine takes effect; the vaccine takes effect immediately in nonpregnant females) was achieved by the third year of the project. ${ }^{10,21,22}$ Thus, the population experienced growth at the onset of the program. During January 2011, the population of 75 comprised 36 females aged $\geq 8 \mathrm{yr}$ in four herds (family units of 28 for Queeny; 16 for Holey Ear; 9 for Kwatile; and 10 for Yvonne) and 12 independent adult males that had left their natal herds ranging in age from $12-15$ yr to $35 \mathrm{yr}$. The animals were habituated to vehicles and were easily accessible for observation from vehicles.

\section{Collaring procedure}

For the first 3 yr of the study period (May 2000May 2003) the elephants were located using traditional tracking methods. In 2003, one elephant (an adult female other than the matriarch and with no infant calf at foot) from each herd was collared $^{20,71}$ with VHF radio collars supplied by African Wildlife Tracking (www.awt.co.za), which facilitated locating a specific herd by means of telemetry. Three collars (Queeny, Holey Ear, and Kwatile) were replaced with global positioning satellite (GPS) satellite collars in October 2007 using the same methods. ${ }^{72}$ The collar units are based on a mobile, global two-way communication platform utilizing two-way data satellite communication complete with GPS systems. Yvonne's herd was not fitted with a satellite collar but retained the standard telemetry collar. Radio collars are frequently used in elephant research $^{18,26,82}$ and are not known to have any adverse effects on the animals onto which they are fitted.

\section{Data collection}

For the 2000-2005 period, a minimum of 3 days was spent in the field per week. Observations were mainly limited to commercial game drive hours ( 0530 to 1100 hours and 1530 to 1800 hours), as they assisted in locating the elephants. The majority of observations were conducted from the research vehicle on the extensive road network. Once the GPS satellite collars were deployed, the collars were programmed to record location data twice a day, in the morning and evening.
When observing the animals, the identities of individuals, the presence and behavior of bulls, the presence of new calves, herd associations, reproductive status, and associated behavior were recorded. To avoid pseudoreplication, one location point was selected per herd per day for each set of home range or association analyses with at least a day between sightings. ${ }^{7,80}$

\section{Vaccinations}

For the first $2 \mathrm{yr}$ of the program, $100 \%$ of all cows of breeding age (cows aged $\geq 10-12 \mathrm{yr})^{56}$ were vaccinated with PZP. ${ }^{23}$ Thereafter, a management decision was taken to allow prepubescent cows to mature, conceive, and give birth to their first calves. They were then vaccinated after the birth of their first calves. This strategy of "planned" pregnancies was modeled through to 2012. ${ }^{21,23,27,28}$ Furthermore, in June 2005, five cows (of which three cows were treated for $5 \mathrm{yr}$, one for $4 \mathrm{yr}$, and one for $3 \mathrm{yr}$ ) and then in June 2007 a single cow, (treated for 2 yr) were removed from treatment to test reversibility of the vaccine to expand on the KNP reversibility studies..$^{10,32}$

The program was initiated in May 2000. As booster vaccinations are administered annually, May 2000 is considered the vaccination birthday (Table 1). By January 2011, 26 animals (i.e., 72\% of all cows $>8 \mathrm{yr}$ ) had been vaccinated.

\section{Vaccination protocol}

In May 2000, all the adult females aged $>12 \mathrm{yr}$ (18 animals) were vaccinated with an initial vaccine of $600 \mu \mathrm{g}$ PZP $+0.5 \mathrm{ml}$ of Freund's Modified Adjuvant (FMA; Sigma Chemical Co., St. Louis, Missouri 63178, USA), following the KNP first trial protocol. ${ }^{10,21,22}$ Thereafter, the 18 target animals received two booster vaccinations of PZP $(600 \mu \mathrm{g})$ emulsified in Freund's Incomplete Adjuvant (FIA; Sigma Chemical Co.) 2-3 wk apart. ${ }^{10,22}$ In 2001 and 2002, five subsequent new cows (two in 2001 and three in 2002) were administered an initial vaccine of $400 \mu \mathrm{g}$ PZP + $0.5 \mathrm{ml} \mathrm{FMA}^{10,22}$ and two booster vaccinations of PZP $(200 \mu \mathrm{g})$ emulsified in FIA 2-3 wk apart. ${ }^{10,22}$ From 2003 onward, new cows were only vaccinated after the birth of their first calves. They received an initial vaccine of $400 \mu \mathrm{g} P Z P+0.5 \mathrm{ml}$ FMA $^{10,22}$ only. Since the time of the second KNP trials, annual boosters were adjusted from $400 \mu \mathrm{g}$ PZP to $200 \mu \mathrm{g}$ PZP, as elephants are very responsive to the vaccine, resulting in the ability to provide lower doses. ${ }^{21}$ 
Table 1. Immunocontraception vaccination birthdays of the Greater Makalali Elephant Population from 2000 to 2011 with treated cows per year and calf births recorded for the period. Adapted from Bertschinger et al. ${ }^{10}$

\begin{tabular}{|c|c|c|c|c|c|c|}
\hline Vaccination period & Year & $\begin{array}{l}\text { Total cows } \\
\text { in population }\end{array}$ & $\begin{array}{c}\text { No. of } \\
\text { treated cows }\end{array}$ & $\begin{array}{l}\text { No. of calves born to } \\
\text { treated dams }\end{array}$ & $\begin{array}{l}\text { No. of calves born to } \\
\text { untreated dams }\end{array}$ & $\begin{array}{l}\text { Reversal calves } \\
\text { (born to cows taken } \\
\text { off treatment) }\end{array}$ \\
\hline Jun 2000-May 2001 & 1 & 33 & 18 & 7 & 0 & 0 \\
\hline Jun 2001-May 2002 & 2 & 36 & 20 & 3 & 2 & 0 \\
\hline Jun 2002-May 2003 & 3 & 36 & 23 & 0 & 3 & 0 \\
\hline Jun 2003-May 2004 & 4 & 36 & 23 & 0 & 2 & 0 \\
\hline Jun 2004-May 2005 & 5 & 36 & 23 & 0 & 2 & 0 \\
\hline Jun 2005-May 2006 & 6 & 36 & 22 & 0 & 1 & 0 \\
\hline Jun 2006-May 2007 & 7 & 36 & 23 & 0 & 0 & 0 \\
\hline Jun 2007-May 2008 & 8 & 36 & 24 & 0 & 0 & 1 \\
\hline Jun 2008-May 2009 & 9 & 35 & 24 & 0 & 0 & 2 \\
\hline Jun 2009-May 2010 & 10 & 36 & 24 & 0 & 1 & 0 \\
\hline Jun 2010-May 2011 & 11 & 37 & 26 & 0 & 3 & 0 \\
\hline Total & & & & 10 & 14 & 3 \\
\hline
\end{tabular}

${ }^{a}$ Untreated dams refers to those individuals that were specifically left off treatment in order that they could conceive and produce their first calves.

\section{Vaccination procedure}

For the 2000-2003 period, the animals were vaccinated from the ground, either from foot or from a vehicle..$^{23}$ The targeted female within the herd was located and darted intramuscularly on the rump at a distance of $15-40 \mathrm{~m} .{ }^{23}$ Vaccinations were administered from a Dan-Inject dart gun using 2-ml Dan-Inject darts and 60-mm smooth (barbless head) needles, which would fall out a short while after impact. The dart was recovered to ensure complete discharge status. Where discharge was incomplete (more than two thirds remaining in the retrieved dart), the animal was revaccinated. ${ }^{23}$ Only 10 animals required revaccination $(0.08 \%$ of the treated population during this period). This was necessary because the animals were not immobilized (which would facilitate hand delivery of the vaccine) and the darts were recovered. ${ }^{23}$

From 2003 to 2011, vaccinations were administered from the air from a helicopter. The methodology is as described in the "Collaring procedure" section above, except that the darts did not contain immobilizing agents but rather the PZP vaccine. Furthermore, disposable Pneu-Dart Mark and Inject darts were used, which consisted of a 2-cc, 13-gauge, 2-inch needle with a Gel collar that enabled darts to fall out and with side ports to ensure injection, even if there was a skin plug in the needle tip. ${ }^{21}$ These darts consisted of a drug and marker chamber filled with a dye (Wonder Mark $^{\circledR}$, Mafuta Products, Republic of South Africa) or similar marking substance (Ginseng Violet or paint). Upon impact, the drug (PZP) was injected from the drug chamber, the marker chamber's plunger was discharged, and the marking substance was sprayed onto the elephant at the dart site. ${ }^{23}$ This procedure facilitated darting and prevented darting the same animal more than once.

\section{Population growth rates}

The contraceptive rate of increase (population rate of increase after contraception implementation) was calculated as the population's growth with regard to births from 1999 (prior to treatment) to 2011, excluding mortalities, introductions, and fatalities (i.e., the "contraceptive effect"). The birth date of calves was recorded as the date on which the calf was first seen.

\section{Spatial responses}

The potential disturbance of darting operations, as demonstrated by shifts in ranging patterns, was tested against two scales: a fine scale (a month on either side of the darting activity) to determine the immediate effects and a broader scale (a year on either side of darting events), which tested the cumulative effect on movement and a potential change in spatial use.

Immediate-short-term disturbance due to PZP treatments: To determine the short-term effects of treatments over time, data sets were categorized into the following vaccination periods for data analysis: year 0 was prior to inception of the contraceptive program (1 June 1999-30 May 2000); year 1 was the initial year of vaccine administration (1 June 2000-30 May 2001); year 
2 was the year of the first annual booster vaccination (1 June 2001-30 May 2002); year 3 was the year of the second annual booster vaccination (1 June 2002-30 May 2003); year 4 was the year of the third annual booster vaccination (1 June 2003-30 May 2004); and year 5 was the year of the fourth annual booster vaccination (1 June 2004-30 May 2005).

The immediate effect of disturbance due to treatment implementation was measured by calculating the herds' 95\% (total range) and 50\% (core range) ) $^{74,99}$ kernel ranges (using a minimum of 30 points $)^{73}$ a month prior to, during, and post(taken as 1 mo after the last dart was fired in that vaccination year) vaccine administration, during the periods March 1999 and August 2004. Fixed 50\% kernel and 95\% kernel home range (KHR) patterns (with $\mathrm{H}=1,000 \mathrm{~m}$ based on preliminary assessment of a range of least-squared estimations) were calculated with Arcview ${ }^{\circledR}$ Version 3.2 (ESRI, Redlands, California 92373, USA) in square kilometers ${ }^{99}$ using Arcview's Animal Movement Analysis extension. ${ }^{36}$ The total range was defined as the smallest area containing $95 \%$ of the distribution. ${ }^{29}$

Vaccinations were administered in the winter months to aid in visibility. Thus, there were no seasonal effects as the combined darting periods (prior, during, and post) all fell within the winter season. Overlap in range patterns was calculated by overlaying maps of the prior behavior ("before darting") with the selected behavior ("during darting" and "after darting") and then dividing the area of overlap by the prior area ("before darting" $\times 100)$ to give a percentage overlap area. ${ }^{74}$ This process was used to determine whether a shift in home range (short-term effect) had occurred subsequent to darting. The greater the percentage overlap, the smaller the change in home range.

To test if treatments resulted in a shift of either core $(50 \%$ kernel) or total $(95 \%$ kernel) ranges during or after darting in individual herds $(n=4)$ and within the Makalali clan $(n=1)$ across all treatment years $(n=1)$ and for each individual treatment year $(n=5)$, a one-way analysis of variance (ANOVA) was used. The dependent variable was the overlap ("before to during darting" and "before to after darting"). The data were subjected to a least significant difference post hoc test to determine if an individual herd's overlap pattern differed significantly from that of others during and after darting and to determine which treatment year had the greatest range shift as a result of darting.
Change in spatial use: The GMPGR expanded by $58 \mathrm{~km}^{2}$ in October 2003, which corresponded with the fitting of GPS-GSM collars to Queeny, Holey Ear, and Kwatile herds. Changes in these herds' spatial use were determined from KHR patterns for each herd during the periods referred to as "years since treatment initiation (YSTI)," as follows: YSTI $=3$ (10 January 2003-10 January 2004); YSTI $=7$ (10 January 2007-19 January 2008); and YSTI = 10 (10 January 2010-10 January 2011). YSTI 0 was not included in the analysis, as this includes the first year of treatment, and, thus, the contraceptive had not yet taken effect and thus a fair comparison regarding the cumulative effects of reduced number of calves could not be drawn. The home ranges were clipped to the reserve boundaries. This study weighted the use of the individual properties within GMPGR (Pidwa North, Pidwa South, Garonga, Makalali, Kristi's, Lufafa, Kgoro, Makhutswi River Game Farms, and Natural Echo) using the utilization distribution from the kernel estimators $^{99}$ to determine each herd's use of each property per YSTI. Significant shifts in ranges (i.e., change in area) were used as a measure of displacement. ${ }^{74}$ Spearman's correlation was used to determine if there was any relationship between rainfall and utilization of the GMPGR properties.

\section{Behavioral responses}

Association and fission-fusion among herds: To determine if there were stable or nonstable associations among the herds, an association index was calculated for each herd per YSTI period, including YSTI 0 (01 October 2000-01 October 2001).

The association index (A.I.) was calculated as follows: ${ }^{34}$

$$
\text { A.I. }=X a b / D+N+X a b,
$$

where $\mathrm{Xab}$ is the number of observations when herd $\mathrm{A}$ and herd $\mathrm{B}$ were seen together, $\mathrm{D}$ is the number of observations where herd $A$ is seen alone, and $\mathrm{N}$ is the number of observations when herd B was seen alone. Observations per herd were required to be at least a day apart so as to provide independent evidence of association. ${ }^{7}$ An association index above 0.1 was used as a nonrandom association signifying social affiliation between two herds. Differences in herd association per herd dyad and per YSTI period was tested using a Kruskal-Wallis test.

To determine if there was a greater degree of fission of herds over YSTIs (i.e., if the herds spent more time alone), the following measure per herd 
per YSTI period was calculated:

Herds alone

$$
=\frac{\begin{array}{c}
\text { Number of observations when } \\
\text { herd A was seen alone }
\end{array}}{\text { Total number of observations of herd A }} \text {. }
$$

Differences in herds alone over the YSTI periods were tested with one-way ANOVA.

Bull presence with herds: To determine whether bull presence with herds increased over the course of treatment, the proportion of time (measured as number of sightings) there were bulls present of the total observations-sightings for each herd per YSTI was calculated. Spearman's correlation was used to determine if there was any relationship between rainfall and bull presence and YSTI periods.

During all sightings in the YSTI periods, the presence or observation of any abnormal behaviors, as predicted by Kerley and Shrader ${ }^{40}$ (including breakouts, female elephant aggression to vehicles (charging of vehicles), tension within family groups resulting in harassment from increasing number of potential allomothers through kidnapping due to an inability to have young) were noted and recorded. Male-male aggression was recorded as being present when interactions between males were more aggressive, resulting in serious attacks with intent to harm (wrestling using trunks and tusks and repeatedly smashing their heads into each other or deliberately tusking each other) ${ }^{57,58}$ rather than sparring (which facilitates the development and maintenance of motor and psychologic responses) ${ }^{13}$ or jostling play (often accompanied by waggling heads, laying of trunks on the other's head, or placing trunks in the opponent's mouth) $)^{57,58}$ used to determine dominance; such increased aggression result in injury in one or both bulls or chasing off, or after, one of the bulls. Female and male aggression, specifically head shaking, mock charging, and charging of vehicles in females and fighting in males (real charge, dueling, tusking and ramming), was assessed based on the classifications and descriptions defined in the Elephant Voices Gesture Database (www.elephantvoices.org) forming the study's ethogram. The duration of sightings lasted $10 \mathrm{~min}$ to $4 \mathrm{hr}$.

Reproductive behaviors: Estrus was recorded as being present when any one or more of the five categories of estrous behavior described by Moss $^{54}$ were present and observed in females at each sighting. Although there are no external morphologic signs of estrus in elephants, ${ }^{54}$ the incidence of estrus is most likely to become apparent in the presence of bulls. ${ }^{61-64}$ All observed musth events that included both urine dribbling and temporal secretions in bulls present at each sighting were recorded. ${ }^{61-64}$ When estrus or musth, or any other associated reproductive behaviors (estrous wariness, walk or chase, consort behavior, mounting or mating), ${ }^{54,56}$ were observed, the specific individuals displaying the behaviors were recorded. Individual musth cycles (onset to end; based on degree of temporal and penal streaming ${ }^{66}$ were calculated based on these data so as to prevent musth events being recorded as multiple musth cycles when they were part of the same musth cycle. Similarly, individual estrous cycles were determined from estrous behaviors displayed by the same individual. With estrous lasting 2-6 days, ${ }^{54}$ multiple estrous behaviors within this window were recorded as the same estrous event. Mate selection (observed consort behavior or matings) and bull hierarchy (musth, age and size) were established according to the criteria defined by Moss and Poole. ${ }^{54,56,66}$

Data were arcsin square root transformed and tested for normality. ${ }^{15,102}$ Where normal (ShapiroWilk: $P>0.05)$, data were contrasted using ANOVA; when not normal, data were tested using a Kruskal-Wallis test. All analyses were conducted in PASW Statistics 18 (SPSS, Inc., Chicago, Illinois 60606, USA).

The multiple contrasts with the same herds may require adjustment of the critical value of $P$ to reduce inflated error rates. Because of the relatively low power of analyses and because the null hypothesis was not rejected, any adjustment would have further strengthened this study's conclusions, so such an adjustment was not included. This study provided statistical test information that will allow readers to make their own assessment in this regard for each test.

\section{Ethical considerations}

The collaring procedure and all vaccinations were administered by Catchco Africa, registered Game Capture Operators with Mpumulanga Parks Board, South Africa. Ethical approval (V049-11) for the use of the vaccine was obtained from the University of Pretoria's Animal Care and Use Committee (project number V049-11). ${ }^{10}$ The Department of Agriculture, Forestry and Fisheries granted permission to conduct research (reference 12/11/1/1/8) in terms of Section 20 of the Animal Diseases Act, 1984 (Act No. 35 of 1984). ${ }^{10}$ The Department of Health's Medicines Control Council issued permits and approval for the "Use of an unregistered medicine in terms of Section 21 
Table 2. Analysis period, respective growth rate, and data source for the Greater Makalali Private Game Reserve elephant study.

\begin{tabular}{ccccc}
\hline Years since treatment initiations & From & To & Growth rate (\%) & Data \\
\hline 0 & 10 Jan 2000 & 10 Jan 2001 & 15 at 01 Jan 2001 & Sightings \\
3 & 10 Jan 2003 & 10 Jan 2004 & 5 at 01 Jan 2004 & Sightings \\
7 & 10 Jan 2007 & 10 Jan 2008 & 1 at 01 Jan 2008 & Sightings and satellite \\
10 & 10 Jan 2010 & 10 Jan 2011 & 4 at 01 Jan 2011 & Sightings and satellite \\
\hline
\end{tabular}

of Act 101 of 1965" (approval number VCT 07/ 2011).

\section{RESULTS}

\section{Population growth rates}

The population growth rates relevant to the YSTI periods are demonstrated in Table 2. The contraceptive effect for each year of treatment is demonstrated in Table 3, updating previous research by Delsink et al. ${ }^{22}$ and Bertschinger et al. ${ }^{10}$ The effect of PZP resulted in an average population rate of increase of $3.5 \%$ for the 20012011 period. Prior to full reproductive control (2003), the average population growth rate was $10 \%$ (2000-2002).

\section{Spatial responses}

Immediate-short-term disturbances due to PZP treatments: Treatments were not disruptive to the Makalali clan across all treatment years and did not cause long-term shifts in the clan's total (95\% kernel) (Wilcoxon signed ranks test for $5 \mathrm{yr}$ separately: all $Z<1.826, N=$ four herds, all $P>$ $0.05)$ and core (50\% kernel) (five tests: all $Z<$ 1.826, $N=$ four herds, all $P>0.05$ ) ranging patterns over the years (Fig. 2A, B).The treatments of herds across all years caused no significant shift in total $(95 \%$ kernel) range among individual herds during (ANOVA: $F_{3,19}=$ $0.427, P=0.736$ ) or after (ANOVA: $F_{3,19}=0.232$, $P=0.873$ ) darting phases over the years (Fig. 3A). Similarly, there was no significant shift in core $\left(50 \%\right.$ kernel) range during (ANOVA: $F_{3,19}=$ 2.032, $P=0.150$ ) or after (ANOVA: $F_{3,19}=1.063$, $P=0.392$ ) darting phases over the years (Fig. 3B). However, there was significant change $(P<0.05)$ in core range between that of Queeny (one of the four named herds) and those of the other herds (Fig. 3A, B). Thus, apart from this herd, the darting did not cause medium-term shifts among individual herds' ranging patterns.

Treatments in individual treatment years resulted in total ranges that were constant for the clan during darting from year to year (ANOVA: $\left.F_{4,19}=0.837, P=0.528\right)$. However, after darting (from year 1, year 2, and year 3), total range position shifted (ANOVA: $F_{4,19}=3.346, P=0.038$ ) (Fig. 4A), probably as a result of the expansion of the reserve.

Core ranges were constant (ANOVA: $F_{4,19}=$ 1.625, $P=0.220$ ) for the clan in individual treatment years during darting. However, there was significant difference in core (50\% kernel) range among the groups for years 1-2 and years 35 ( $P<0.05$ for both) (Fig. 4B). The clan's core ranges remained unchanged (ANOVA: $F_{4,19}=$ $1.723, P=0.197)$ after darting. However, the core

Table 3. Population rate of increase after contraception implementation for the Greater Makalali Elephant Population from 1999 to 2011.

\begin{tabular}{|c|c|c|c|c|c|c|c|c|c|c|c|c|c|}
\hline & 1999 & 2000 & 2001 & 2002 & 2003 & 2004 & 2005 & 2006 & 2007 & 2008 & 2009 & 2010 & 2011 \\
\hline Total population size at Jan $1999^{a}$ & 47 & & & & & & & & & & & & \\
\hline Calves born during the year & 2 & 5 & 8 & 4 & 0 & 3 & 2 & 0 & 1 & 1 & 1 & 2 & 3 \\
\hline Effective population size ${ }^{b}$ & 49 & 54 & 62 & 66 & 66 & 69 & 71 & 71 & 72 & 73 & 74 & 76 & 79 \\
\hline $\begin{array}{l}\text { Contraceptive rate of increase } \\
\text { (i.e., contraceptive effect } \\
\text { [excludes mortalities and } \\
\text { introductions]) }\end{array}$ & & 1.10 & 1.15 & 1.06 & 1.00 & 1.05 & 1.03 & 1.00 & 1.01 & 1.01 & 1.01 & 1.03 & 1.04 \\
\hline
\end{tabular}

a Total population size for 2004 through 2011 includes eight births to untreated prepubertal cows allowed to produce their first calves. (Age of first calving is based on that observed on the reserve prior to contraception.)

${ }^{\mathrm{b}}$ Effective population size excludes eight adult males that broke into the reserve (three in 2000, two in 2001, two in 2005, and one in 2006) and two calf mortalities (two in 2000) and one natural adult cow mortality (2008), as these should be excluded when considering the effect of the contraception program. 
(A)
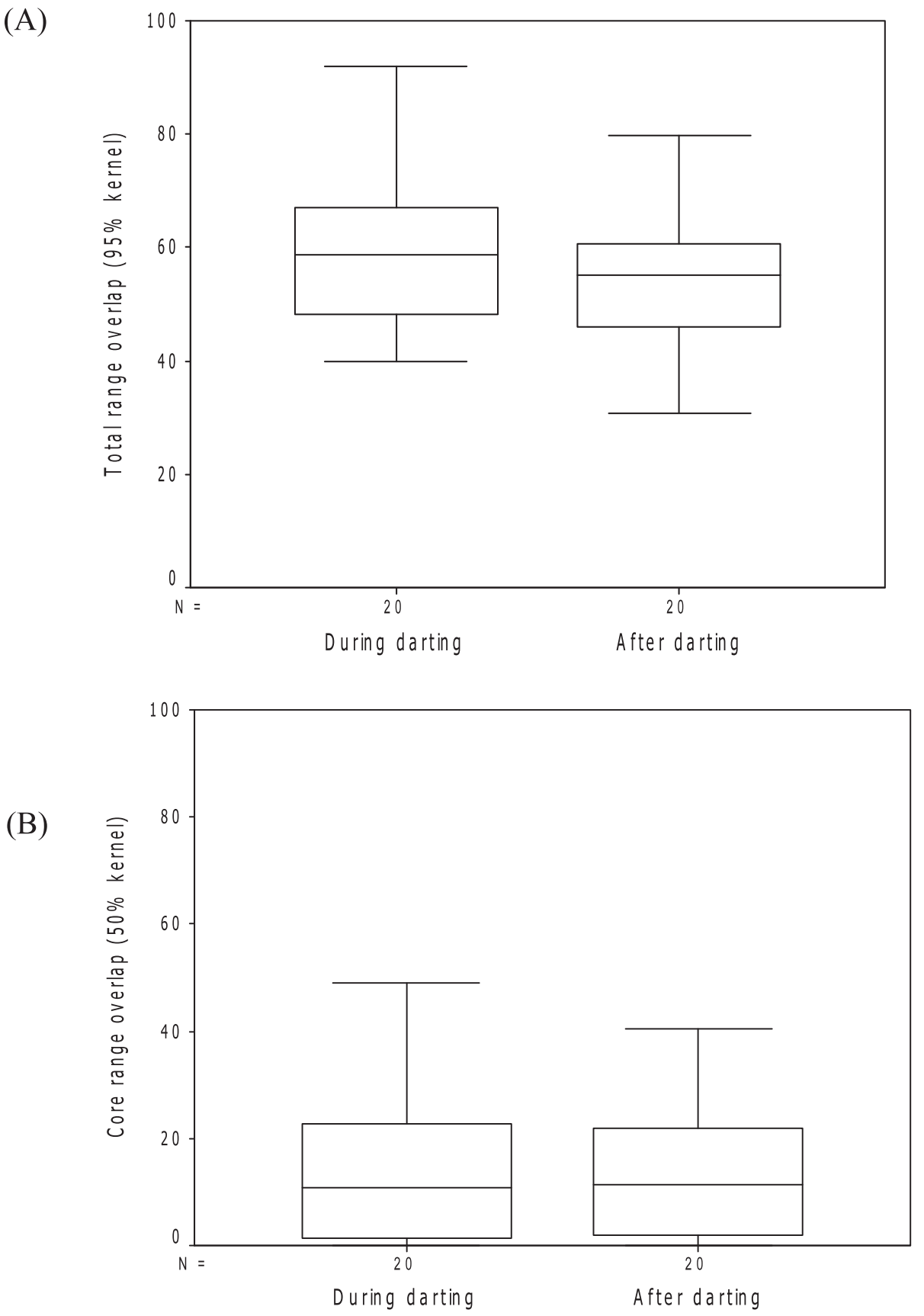

Figure 2. Effect of treatments on clan home ranges' (A) total range overlap (95\% kernel) and (B) core range overlap (50\% kernel) with ranges before darting.

range in year 3 was significantly larger than in all other years $(P<0.05$ for all) (Fig. 4B).

Treatments of individual herds $(n=4)$ over individual treatment years $(n=5)$ did not significantly shift their total (Wilcoxon signed-ranks test: $Z=-1.755, N=20, P=0.079)$ or core $(Z=$
$-2.01, N=20, P=0.841)$ ranges in response to the darting during treatment years.

Change in spatial use: The utilization was not even per GMPGR property among the YSTI periods [Kruskal-Wallis: $\mathrm{H}(9)=7.2, P=0.027$ in Pidwa North; $\mathrm{H}(9)=7.2, P=0.027$ in Makalali; 
(A)

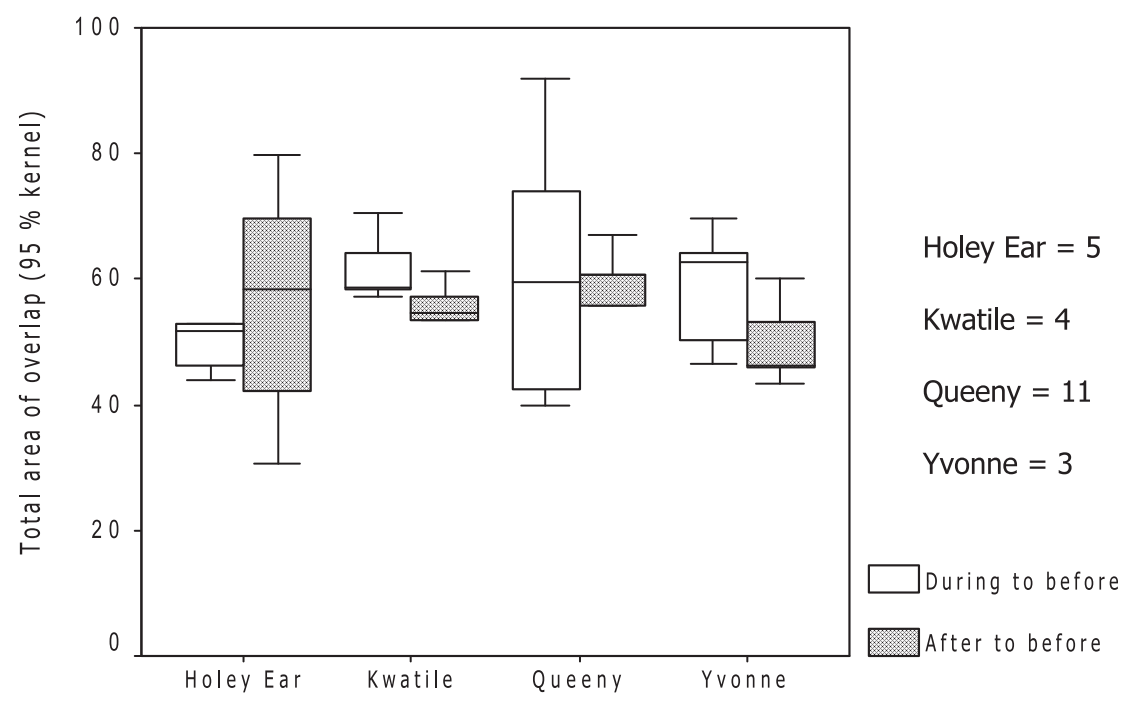

HERD

(B)

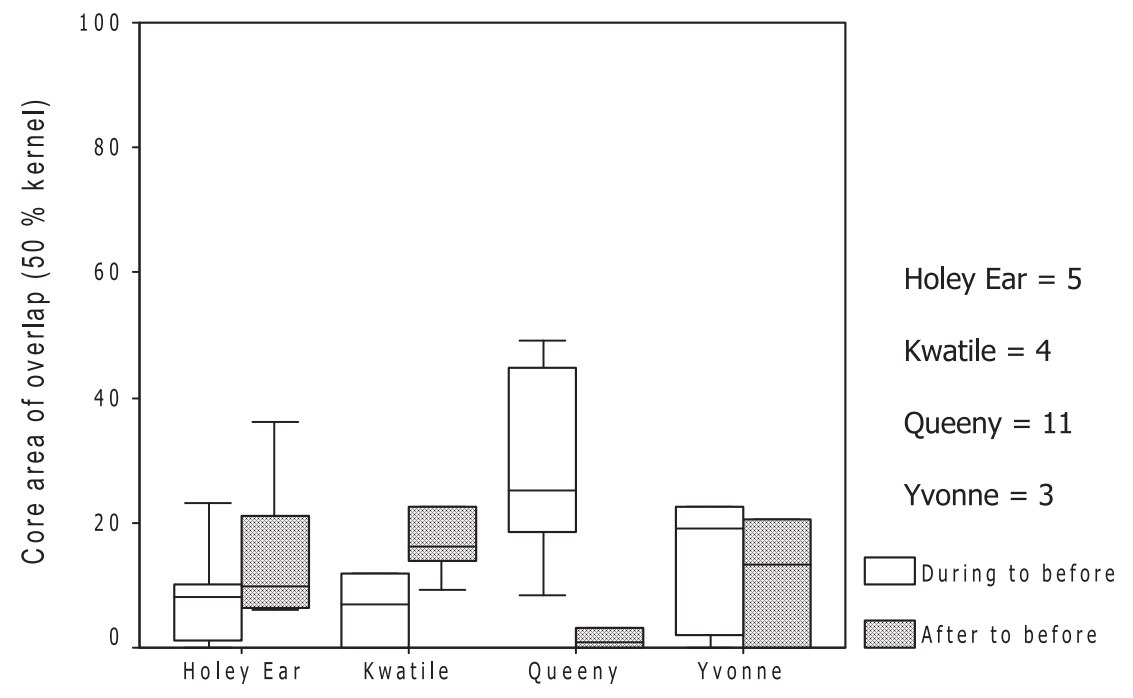

HERD

Figure 3. Change between individual herd ranges during and after darting phases over the years. (A) Total range overlap (95\% kernel) and (B) core range overlap (50\% kernel). Number of contrasted vaccinated events $=5$ yr for each herd. Numbers correspond to the number of vaccinated cows within each named herd.

$\mathrm{H}(9)=7.62, P=0.022$ in Kristi's, and $\mathrm{H}(9)=6.214$, $P=0.045$ in Kgoro] (Fig. 5). There was a significant increase in use of Pidwa North with increasing rainfall [Spearman's correlation: $r_{s}(9)=0.949, P<$ $0.001]$, with significantly less use of Makalali $\left[r_{s}(9)\right.$ $=-0.949, P<0.001]$ and $\operatorname{MRGF}\left[r_{s}(9)=-0.738, P=\right.$ 0.023 ] with increasing rainfall (Fig. 6). The utiliza- tion per GMPGR property was even among herds (Fig. 7).

\section{Behavioral responses}

Fission-fusion among herds: Nonrandom social associations occurred among all herds over all YSTI periods (A.I. > 0.1), except between Holey 
(A)

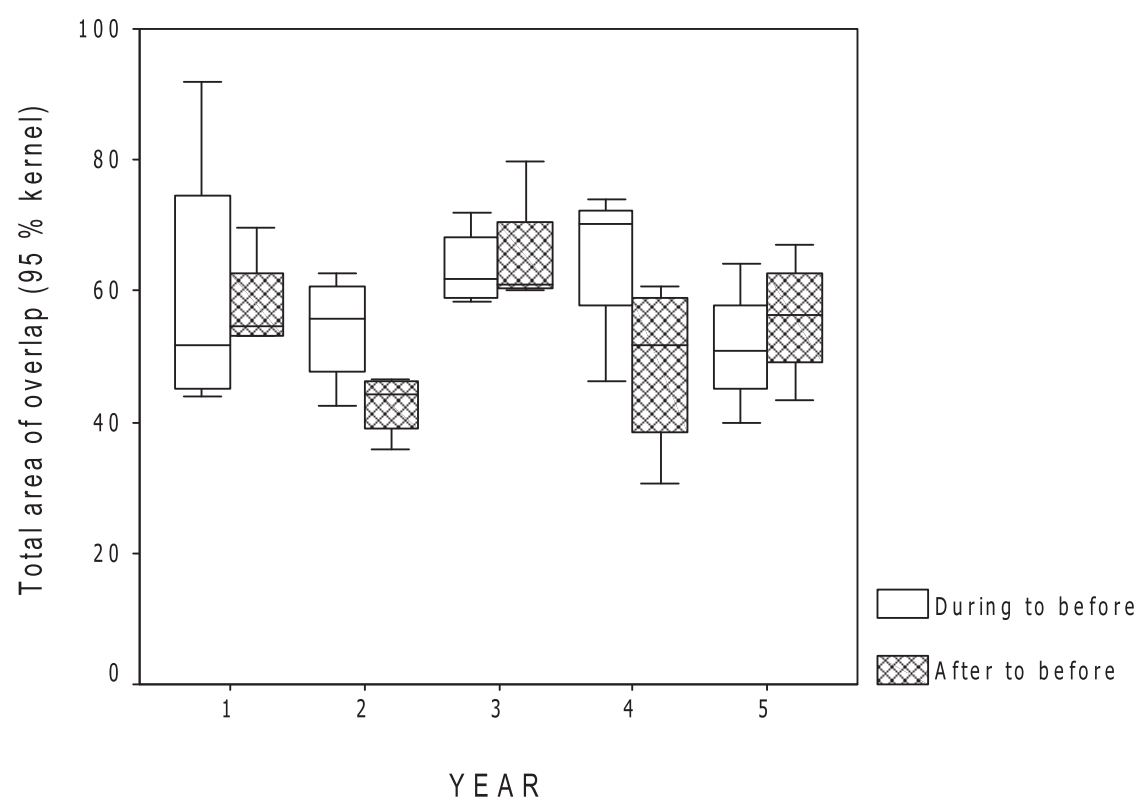

(B)

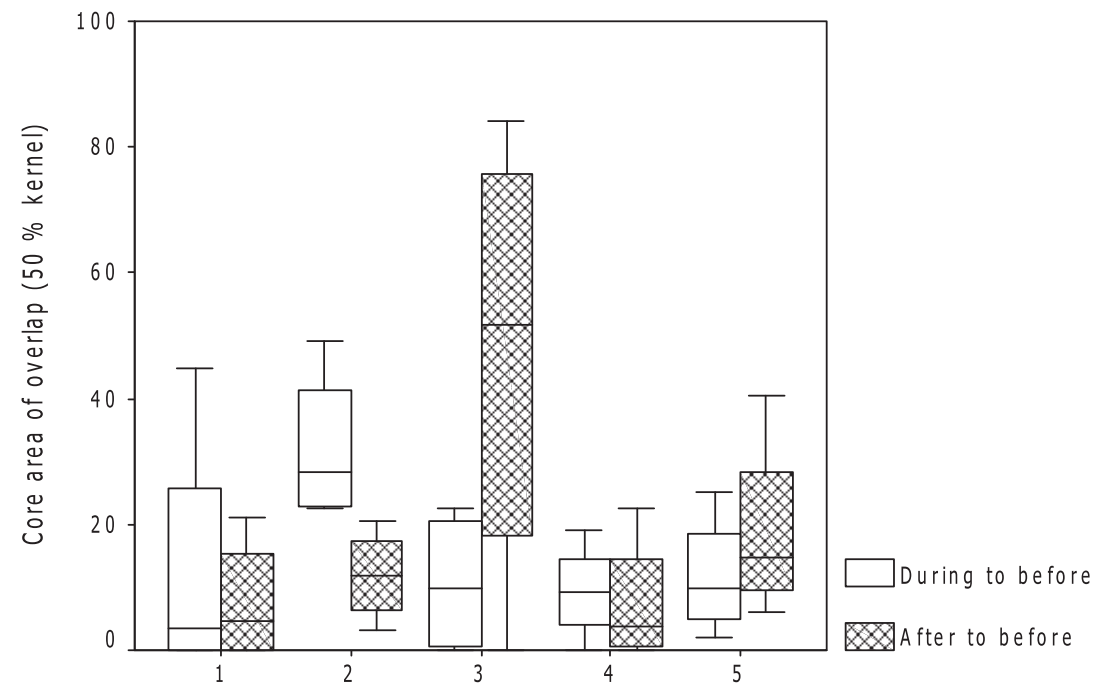

YEAR

Figure 4. Overall change of Makalali clan ranges during and after darting over the years of treatment. (A) Total range overlap (95\% kernel) and (B) core range overlap ( $50 \%$ kernel). Number of contrasted vaccinated events $=5$ yr for all herds. See text for definition of years.

Ear and Queeny in YSTI 0 (A.I. < 0.1). An A.I. $\geq$ 0.5 was considered a strong association, with herds nonrandomly associating $50 \%$ of the time. There were no significant changes in association among YSTIs [Kruskal-Wallis: $\mathrm{H}(24)=6.144, P=$ 0.105] (Fig. 8A). Association was not the same for all possible dyads [Kruskal-Wallis: H(24) = 11.939, $P=0.036$ ]. The dyad for Kwatile and 


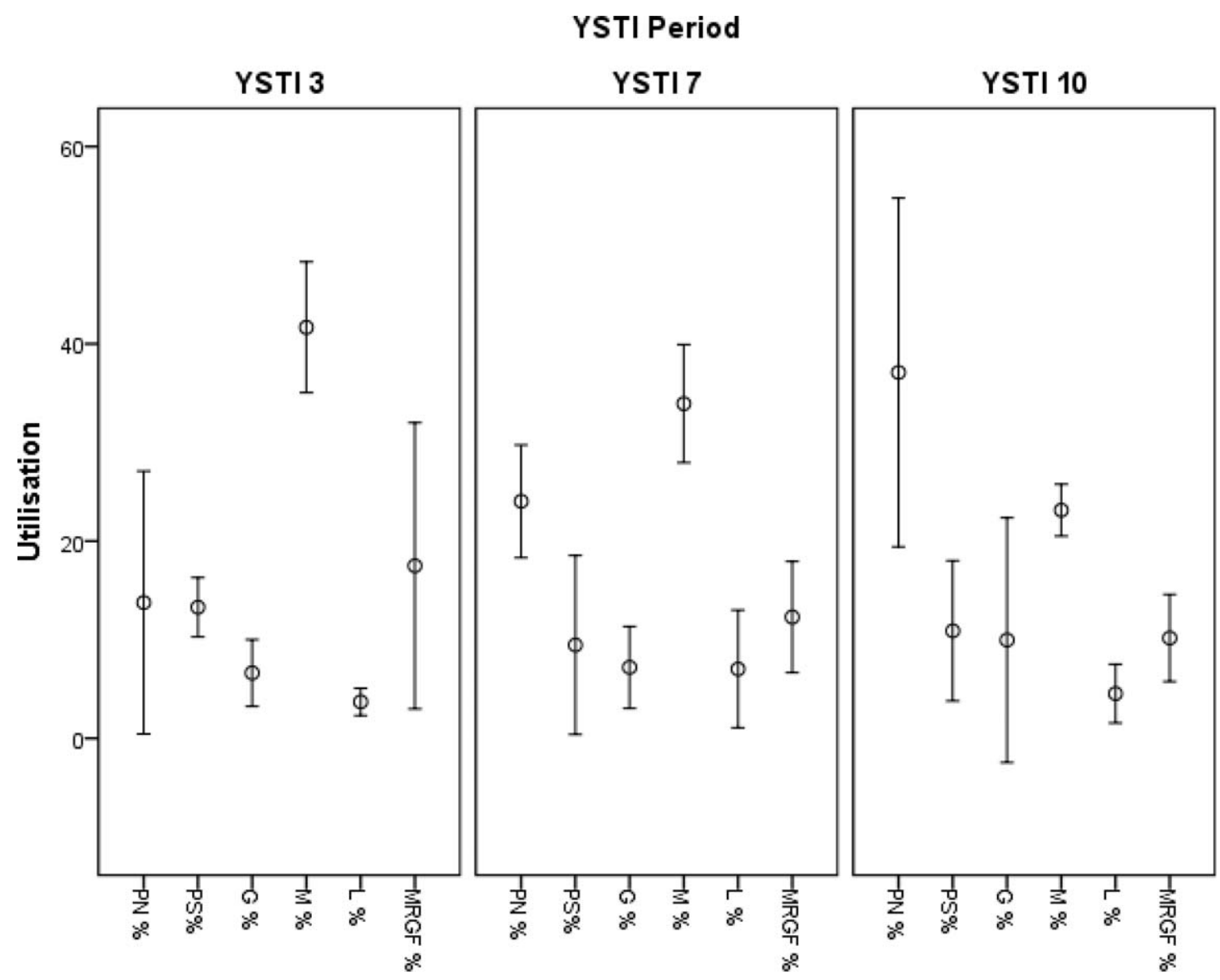

Figure 5. Utilization of the Greater Makalali Private Game Reserve properties by the Makalali clan among "years since treatment initiation" periods (Oct 2003/2004, Oct 2007/2008, and Oct 2010/2011). PN = Pidwa North; PS = Pidwa South; $\mathrm{G}=$ Garonga; $\mathrm{M}=$ Makalali; $\mathrm{L}=$ Lufafa; and MRGF = Makhutswi River Game Farms. The properties Kgoro, H90, and H26 are not illustrated here because of their small size ( $<700$ ha for all).

Yvonne had the highest mean rank, and with an A.I. $>0.5$ for all periods, it was significantly different from all other dyads (Mann-Whitney $U$ test: $U=0.0, P=0.021$ ) (Fig. $8 \mathrm{~B}$ ).

There was no significant difference in observations of herds alone among YSTI periods (ANOVA: $F_{3,12}=0.605, P=0.624$ ) (Fig. 9A). There was a significant difference in proportion of herds alone across YSTI periods (ANOVA: $F_{3,12}=$ 13.696, $P<0.01$ ) (Fig. 9B). The proportion of time spent alone by Holey Ear $(1.52 \pm 0.28)$ was significantly higher than by Kwatile $(0.98 \pm 0.14$, Tukey post hoc test: $P=0.012)$ or Yvonne $(0.79 \pm$ $0.15, P=0.001)$. Similarly, time spent alone by Queeny $(1.50 \pm 0.17)$ was significantly higher than by Kwatile $(P=0.015)$ and Yvonne $(P=0.001)$. There were no statistically significant differences among the other herds $(P>0.05)$. Yvonne's herd showed the lowest proportion of time spent alone (Fig. 9B).

Bull presence with herds: Bull association with herds was not even among YSTI periods [Kruskal-Wallis Test: $\mathrm{H}(16)=9.118, P=0.028$, with a significant difference between YSTI 0 and YSTI 7 (Mann-Whitney $U$-test: $U=1.0, P=0.43$ ) and between YSTI 0 and YSTI $10(U=0.5, P=0.028)$. There was a significant decrease in bull presence over YSTI periods [Spearman's correlation: $r_{s}(16)$ $=-0.776, P<0.001$ ] (Fig. 10A). Bull presence was the same among herds $[\mathrm{H}(16)=1.416, P>0.05]$ (Fig. 10B).

General: Of the 994 herd sightings for the periods YSTI 0, 3, 7, and 10, no female breakouts were recorded, female elephant aggression to vehicles through charging of vehicles was recorded 13 times $(1.3 \%)$, and no kidnappings by either young allomothers or older treated cows with no 
A) Pidwa North

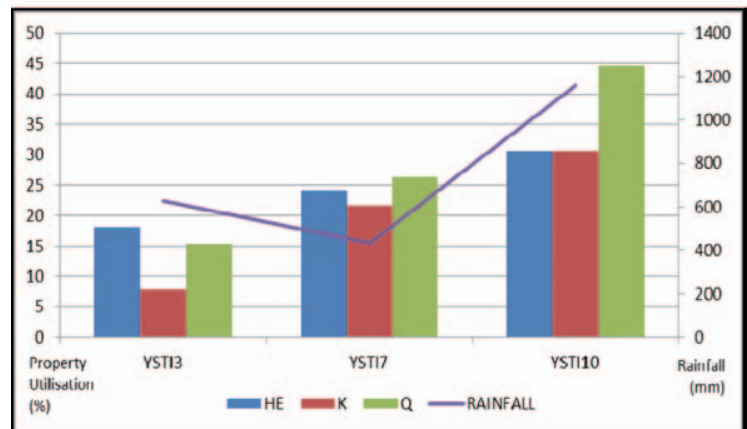

B) Makalali

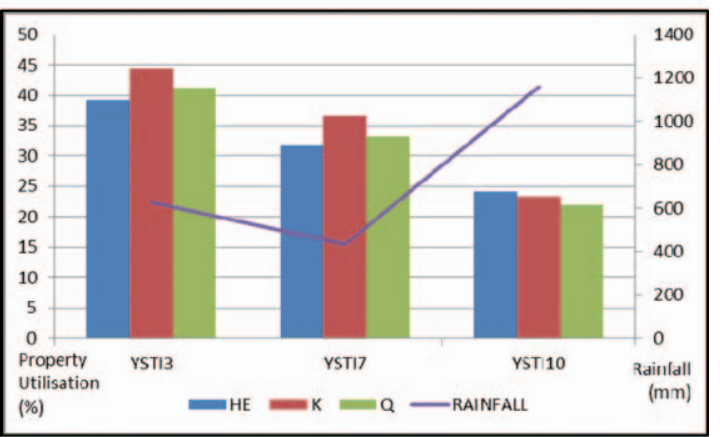

\section{C) Makhutswi River Game Farms}

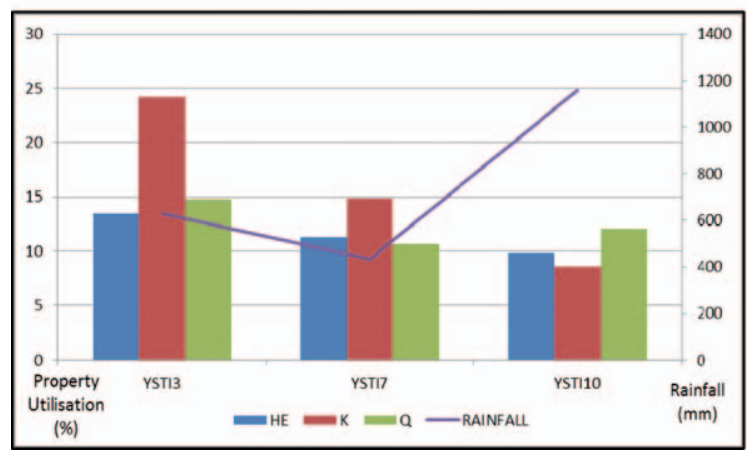

Figure 6. Correlation between Greater Makalali Private Game Reserve property utilization and rainfall by individual herds per "years since treatment initiation" periods (Oct 2003/2004, Oct 2007/2008, and Oct 2010/ 2011). HE = Holey Ear; $K=$ Kwatile; and $Q=$ Queeny.

calves were recorded. Of the 534 bull sightings (alone, with herds, or with other bulls) for the periods YSTI $0,3,7$, and 10 , five $(0.9 \%)$ malemale aggression encounters were recorded. Thus, as per the definitions of Kerley et al., ${ }^{39}$ no abnormal or severe elephant behaviors were observed.

\section{Reproductive behaviors}

During YSTI 0, 3, 7, and 10, 17 musth events, three matings, two consorts, four estrous chases, and three estrous walks were recorded. Within the GMPGR, the timing of musth periods in individuals is dependent on the temporal patterning of musth in other males. Musth was staggered among the bulls, with no two bulls being in musth at the same time, a possible product of the enclosed reserve. The two largest GMPGR bulls demonstrated the greatest reproductive behaviors (Table 4). On average, Charles displayed the longest musth cycle of approximately 4-6 wk every 3 mo.

\section{DISCUSSION}

This study investigated the effects of sustained use of PZP as a contraceptive management tool over the course of $11 \mathrm{yr}$ on cow and bull societies and their behavior by assessing responses in spatial and behavioral contexts. Ranging behavior was used to assay for more subtle changes that are not necessarily externally apparent but that could indicate underlying stress or anxiety. ${ }^{38,90,98}$ Other such indicators include grouping behavior and associations. ${ }^{33,98}$

Although there was avoidance behavior in relation to ground darting, the cumulative effect of vaccine administration did not cause changes in ranging, grouping, or associations over the short term (2000-2004), supporting the findings of Druce et al. $^{27}$ As herds increasingly associated the darting team with ground darting, time taken 


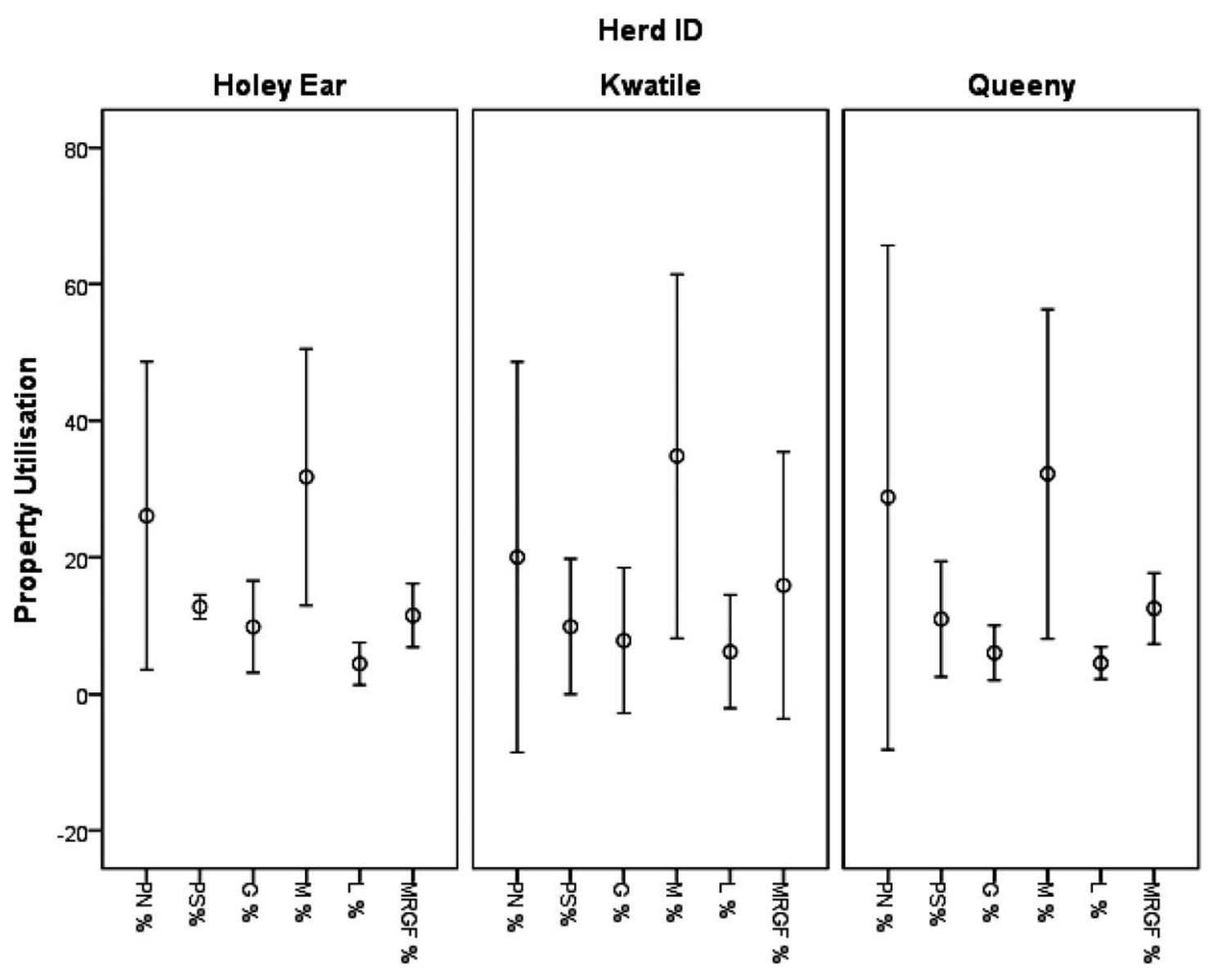

Figure 7. Utilization of the Greater Makalali Private Game Reserve properties by individual herds across the "years since treatment initiation" periods (Oct 2003/2004, Oct 2007/2008, and Oct 2010/2011). PN = Pidwa North; PS = Pidwa South; $\mathrm{G}=$ Garonga; $\mathrm{M}=$ Makalali; $\mathrm{L}=$ Lufafa; and MRGF = Makhutswi River Game Farms. The properties Kgoro, H90, and $\mathrm{H} 26$ are not illustrated here because of their small size ( $<700$ ha for all).

for vaccine administration of all individuals during year 3 was increased to 25 days. ${ }^{23}$ In contrast, the helicopter darting conducted in years 4-10, was far more efficient and was completed within $30 \mathrm{~min} .{ }^{20,23}$ With the change to helicopter darting, the elephants no longer associated the darting with the research team. Thus, the shorter vaccine administration achieved by the helicopter darting resulted in the fewest behavioral consequences in the short term with regard to wariness and avoidance behavior of the research team and change in spatial use, and this administration technique is recommended from a behavioral perspective. ${ }^{11}$

Many of the small reserves in South Africa that house elephants are ecotourism destinations, and our results indicate low risk from an implementation perspective for ecotourism activities, as elephants were continually observed by tourists (Delsink, pers. obs.). ${ }^{27}$

While it is true that nonbreeding females will have lower energy requirements, as they are not pregnant or lactating, it remains to be seen if PZPtreated females will utilize different habitats by shifting their home ranges and thus altering the impact on the ecosystem in the long term..$^{40}$ In general, herds with small calves remain fairly close to water, and, thus, it is predicted that PZPtreated cows are likely to move farther away from water, resulting in more widespread impacts across the landscape. ${ }^{40}$ However, there was no apparent effect of PZP through major shifts in spatial use as a result of altered nutritional requirements and fewer calves within the reserve. Water, specifically the river systems and the influence of rainfall (which governs the presenceabsence of pools within the rivers), appears to be 
A)

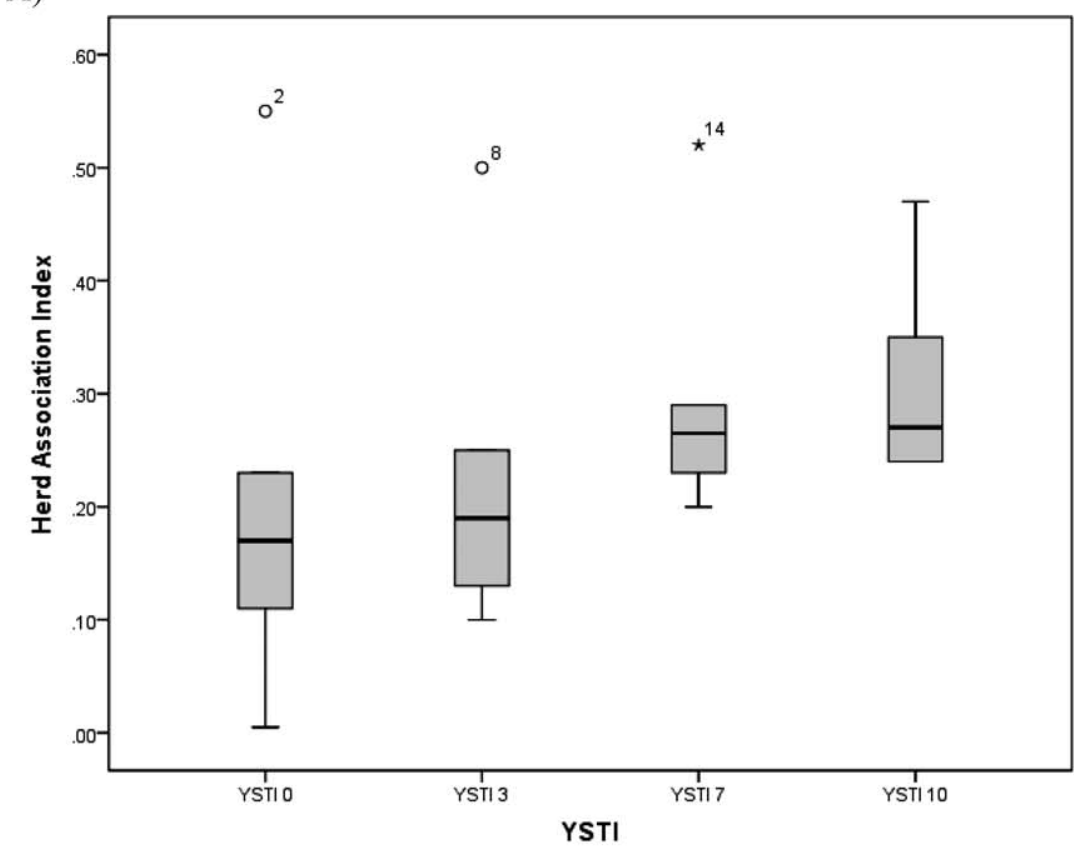

B)

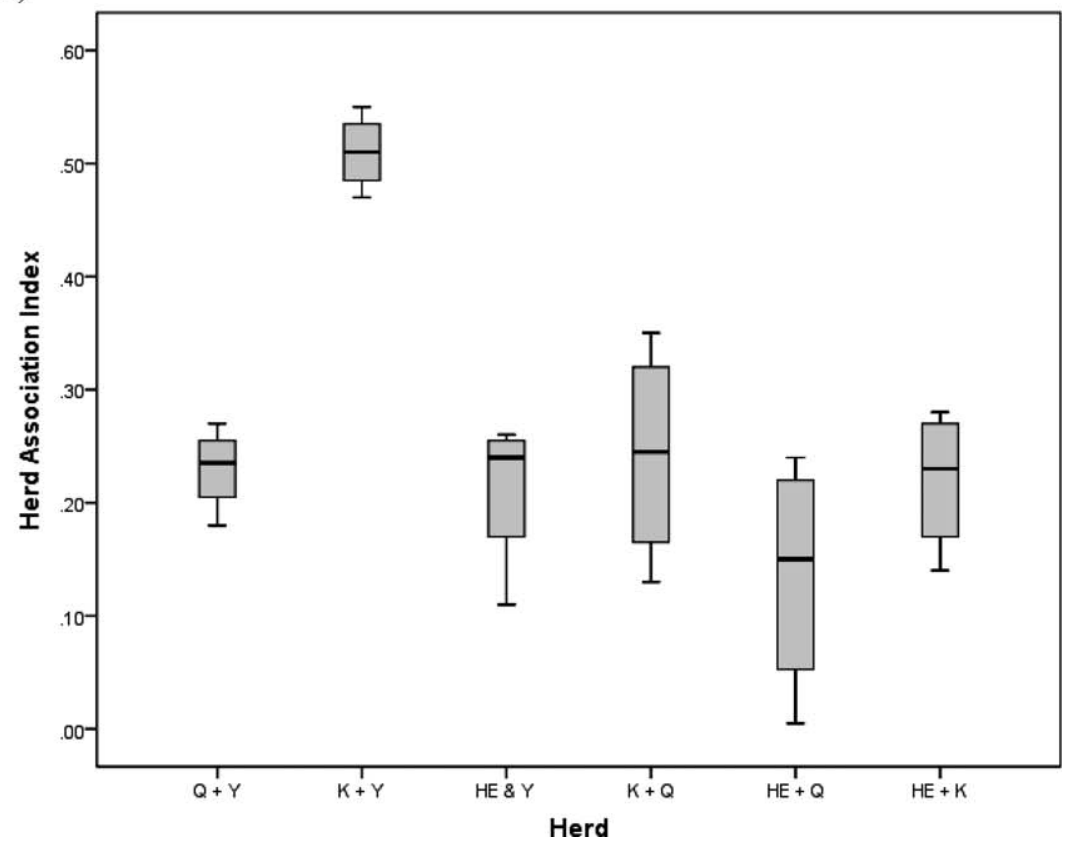

Figure 8. Association indices of the Greater Makalali Private Game Reserve elephant herds dyads (A) per "years since treatment initiation" (YSTI) period (Oct 2000/2001, Oct 2003/2004, Oct 2007/2008, and Oct 2010/ 2011) and (B) across YSTI periods (Oct 2000/2001, Oct 2003/2004, Oct 2007/2008, and Oct 2010/2011). HE= Holey Ear; $\mathrm{K}=$ Kwatile; $\mathrm{Y}=$ Yvonne; and $\mathrm{Q}=$ Queeny. Markers refer to case numbers of highest-lowest values for that category. 
A)

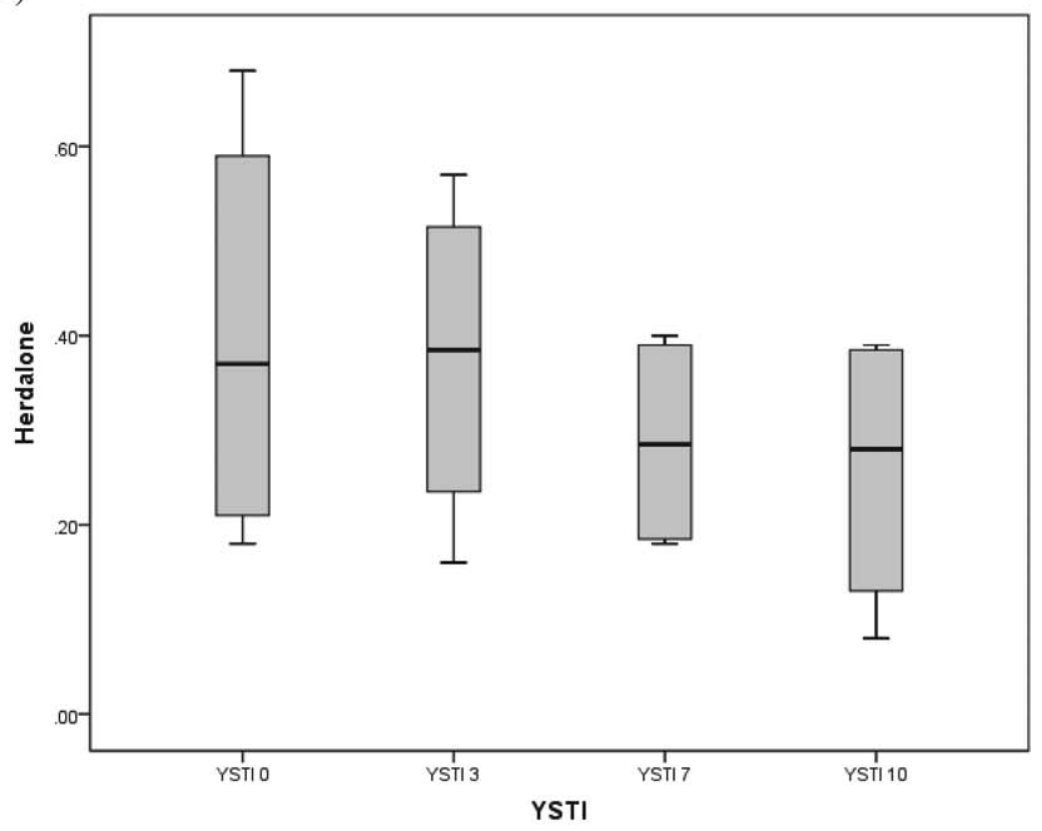

B)

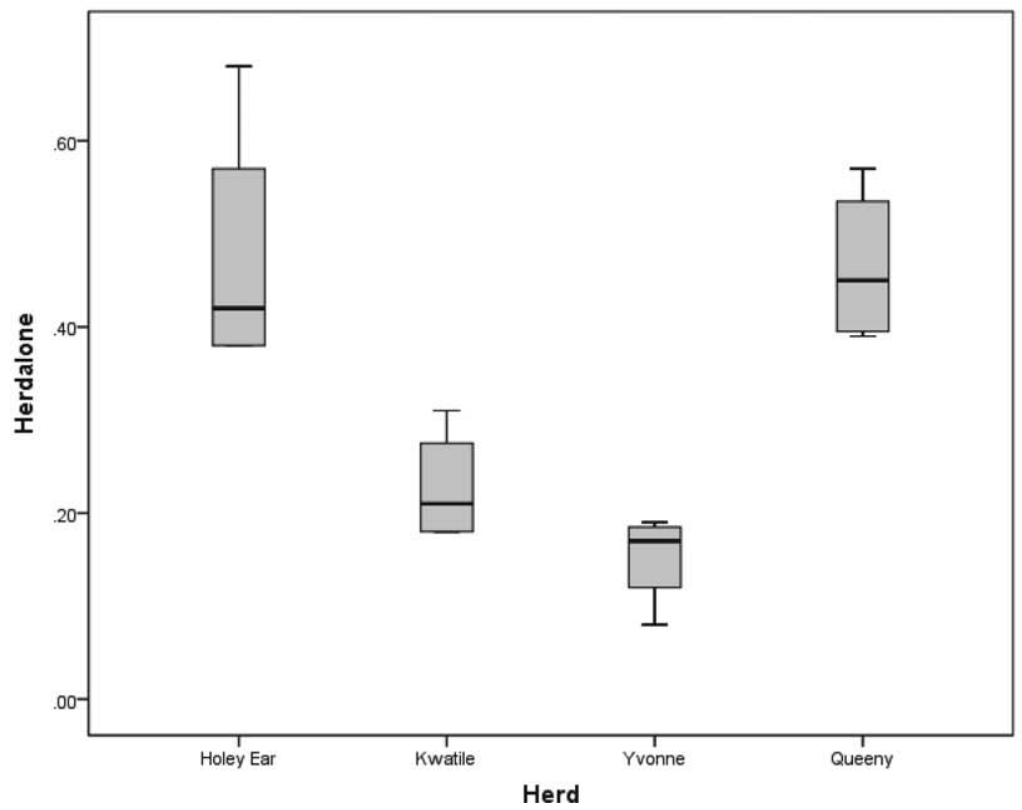

Figure 9. Proportion of time spent alone of the Greater Makalali Private Game Reserve clan (A) per "years since treatment initiation" (YSTI) period (Oct 2000/2001, Oct 2003/2004, Oct 2007/2008, and Oct 2010/2011) and (B) of individual herds across $(n=$ four herds) YSTI periods (Oct 2000/2001, Oct 2003/2004, Oct 2007/2008, and Oct 2010/2011). 
A)

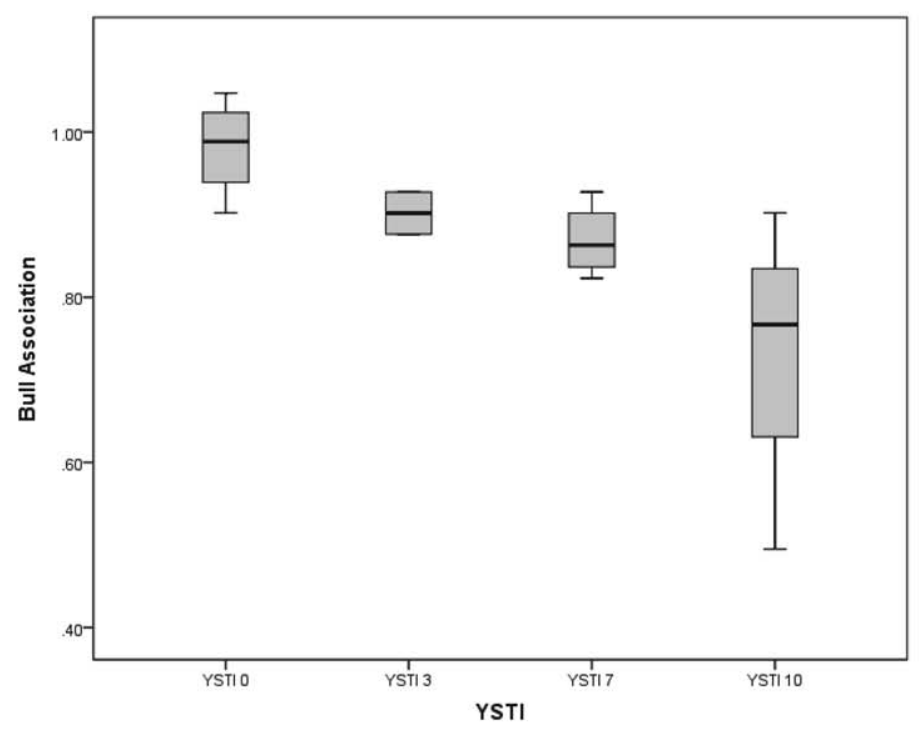

B)

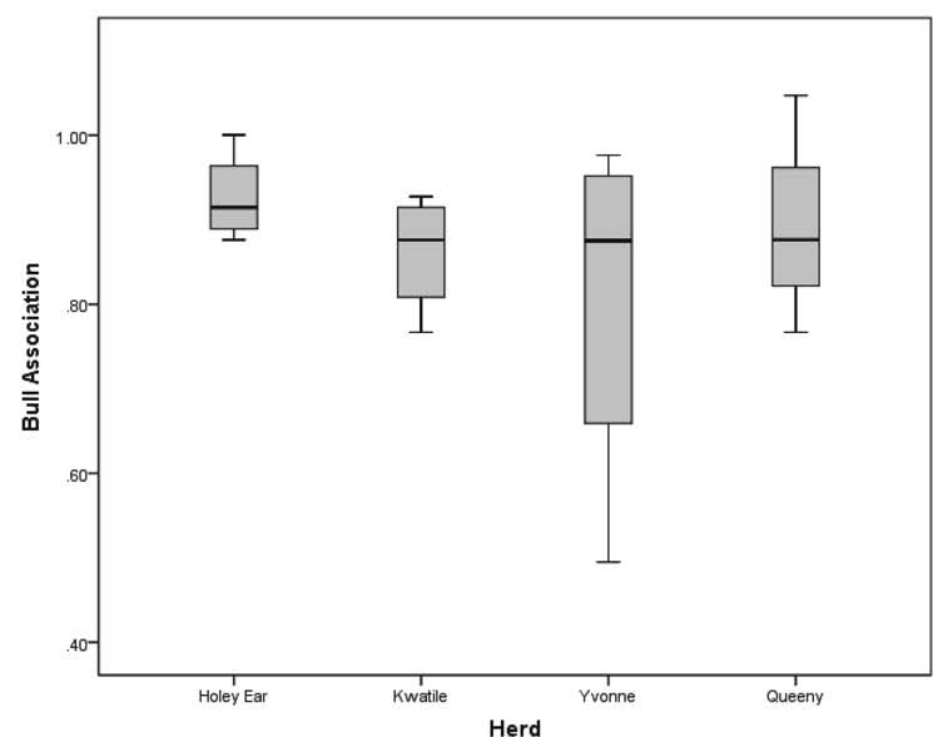

Figure 10. Bull association with herds for (A) the Greater Makalali Private Game Reserve elephant clan across "years since treatment initiation" (YSTI) period (Oct 2000/2001, Oct 2003/2004, Oct 2007/2008, and Oct 2010/ 2011) and (B) individual herds across YSTI periods (Oct 2000/2001, Oct 2003/2004, Oct 2007/2008, and Oct 2010/2011). 
Table 4. Reproductive and sexual behaviors of the Greater Makalali elephant population during "years since treatment initiation" periods 3, 7, and 10 (Oct 2003/2004, Oct 2007/2008, and Oct 2010/2011).

\begin{tabular}{lccccrr}
\hline Bull identification & Musth & Mating & Consort behavior & Estrous chase & Estrous walk & Total \\
\hline Charles & 11 & 1 & 1 & 1 & 1 & 14 \\
Riff Raff & 4 & 1 & 1 & 2 & 1 & 9 \\
Bombyx & 1 & & & 1 & 1 & 3 \\
Windgat & 1 & 1 & 2 & 4 & 3 \\
Unidentified & 17 & 3 & & & 1 \\
Total & & & & & 1 \\
\hline
\end{tabular}

the main driver of elephant ranging on GMPGR despite sustained treatment and a reduced number of small calves, evidence against the concern raised by Kerley and Shrader. ${ }^{40}$

Male calves associate with their mothers until they are up to $10-12$ yr of age, while female calves remain in their natal herds, ${ }^{3,55,56,97}$ and in this regard, the resource needs of breeding groups are not substantially changed as new calves are born into the herds according to the herd's intercalving intervals or the immunocontraceptive strategy, and calves of various ages are present within the herd, albeit in fewer numbers. As indefinite periods of $0 \%$ growth rate are not recommended or currently practiced, ${ }^{10,21,28}$ it is unlikely that spatial responses will be detected because there will always be calves present, albeit in fewer numbers.

While elephants remain closely tied to their natal herds, they live in fluid, fission-fusion societies, in which the composition of group members changes over the course of hours, days, or seasons as core and bond groups merge and diffuse. ${ }^{3,56,96}$ At the GMPGR, the strong degree of association between Kwatile's and Yvonne's herds points to the two being a bond (the association of two or more core social groups that repeatedly and consistently fuse to form larger groups) or kinship (the matrilocal group increases in number and the core group splits) group. ${ }^{3,56,96}$ This is supported by the capture history that records that these two groups were caught on the same day and from the same region. That the bond-kinship group association between Kwatile and Yvonne has remained intact $11 \mathrm{yr}$ posttreatment, despite the variation in calf numbers and treated cows, is testimony to the lack of social consequence of sustained PZP treatment.

The minor shifts in herd fusion proportions near the start of the study were attributed to the general pattern of group formation that has been seen in other small reserves with reintroduced populations, such as Pilanesberg National Park,
Hluhluwe-Umfolozi Park, and Phinda Game Reserve. ${ }^{29}$ Females tended to form a single large group, followed by fission into increasingly smaller groups as the elephants acclimatized. At GMPGR, the integrity of the herds remained strong and stable; families without calves or with reduced numbers of calves did not seek out and join families that had calves. ${ }^{40}$ Conception was not completely eliminated through the planned pregnancy and reversal studies, although it was $100 \%$ effective in treated females, and calves continue to be born in all herds, albeit in fewer numbers. Management concerns of PZP implementation, such as herd fragmentation, isolation, and alterations in matriarchal group size, were not demonstrated. ${ }^{40,59}$

No notable changes in matriarchal behavior, mother-offspring associations, or male-female interactions were detected. There were also no noticeable effects of PZP contraception on estrous or musth behaviors during the study period, with cow mate-selection processes intact and bull hierarchy unaffected. These results are in contrast to the abnormal behaviors associated with the hormonal contraception program piloted in KNP using estradiol implants, which was rapidly ended as a result of severe behavioral anomalies. ${ }^{32,94}$

Under the PZP treatment, target animals display normal estrous cycles, cycling approximately 15-16 wk, ${ }^{8,11}$ because, although copulation still occurs, conception does not. Therefore, under treatment, the frequency of mating and its accompanying disturbances are assumed to be far more frequent. ${ }^{40,94}$ With an increased frequency of estrus, there is the potential for change in the frequency of association of both sexually active musth and sexually active non-musth bulls with breeding herds as both sets of males compete for estrous females. ${ }^{61}$ The contrary was observed, with bull presence with herds decreasing over the years of treatment (with YSTI 10 having the lowest association), probably an effect of aging in this relatively young population. However, two 
studies in which fecal progestagens were monitored in one reserve with PZP contraception ${ }^{2}$ and in another with no bulls ${ }^{8}$ demonstrate that seasonal anestrus was common during the dry season, as were irregular cycles. This means that free-ranging elephant cows do not necessarily cycle continuously and regularly if they do not fall pregnant, which could further explain the lack of consequence of bull association.

The non-musth sexually active bulls did not increase their associations with the herds. While there was no significant increase in estrus between herds and years of treatment and while we may have underestimated some estrous behavior as a result of difficulties in making observations in thick bush, consort and mating behavior was dominated by the same dominant bulls, indicating that estrous females solicited guarding from musth males and older, therefore more dominant, males preferentially. ${ }^{54}$ Thus, the treatments did not alter any typical female choice and male-male competitive mechanisms, ${ }^{31,54}$ with musth bulls dominating above all others. ${ }^{3,62-64}$

Increased male-male aggression over mating opportunities due to more frequent estrus of females was not observed. ${ }^{40}$ Within the GMPGR population, there are more independent (i.e., already left the natal herd) sexually active nonmusth bulls $(n=7)$ than there are sexually active musth bulls $(n=5)$, and while the sexually active non-musth bulls did not increase their associations with the herds, there was also no increased aggression between them (Delsink, pers. obs.).

In year 3, management revised the vaccination protocol and only vaccinated young cows after the birth of their first calves. Of the six cows removed from treatment in 2005 and 2007, respectively, to test vaccine reversibility, three reversed, producing calves that would have been conceived $18 \mathrm{mo}$ (for a 5-yr- and 2-yr-treated cow) and $29 \mathrm{mo}$ (for a 3 -yr-treated cow) after the cessation of treatment. ${ }^{10}$ These three reversal calves comprised $11 \%$ of the total number of calves born during the study. This allowed for growth at a much reduced and controlled rate and would allow allomothering and learning opportunities to exist for yet-to-be mothers. ${ }^{40}$ More importantly, elephant calves have a large impact on both the herd and the individual's social well-being. ${ }^{56}$ Interactions between cows and calves help stabilize relationships, both within and between family groups..$^{40}$ With the "planned" pregnancy strategy and ultimately the reduction in growth rate, none of the hypothetical concerns raised by Kerley and Shrader ${ }^{40}$ were demonstrated.
The KNP trials ${ }^{32}$ and this GMPGR study have culminated in approximately $16 \mathrm{yr}$ of intensive investigation into the social and behavioral consequences of immunocontraception application in African elephants. ${ }^{10,11,21,27,28}$ However, the GMPGR study may be considered as a mediumterm study only because its 11-yr duration, as presented herein, covers the time period in which one cohort of offspring becomes sexually mature. Longer-term effects (with sustained treatments of $>11 \mathrm{yr}$ ) are still possible and unknown in elephants as a result of their extreme longevity. Inferences can, however, be made from similar studies that have been conducted on other longlived animals (i.e., horses), with same-population studies spanning more than $25 \mathrm{yr}$ on Assateague Island National Seashore. ${ }^{21,42,44,45,84}$ The horse studies demonstrated that after sustained use of the immunocontraceptive, horses are in better condition, have lower mortality rates and longer life spans (with treated animals developing new age classes; i.e., $21-25 \mathrm{yr}$ and $>25 \mathrm{yr}$ ). ${ }^{21,42,45,84}$ The Makalali study is the longest-running study on immunocontraception in African elephants, but there are no data to contrast with the findings of the horse studies (i.e., that elephants will live longer and form new age classes). Elephant longevity is governed by the eruption of molars, with the last set erupting at around age $47 .{ }^{47}$ Elephants may experience longevity of greater than $60 \mathrm{yr}$, but few do. ${ }^{5}$ Thus, it is unlikely that concerns regarding extended impact on habitat as a result of new age classes forming as a result of PZP treatment in elephants ${ }^{40}$ are well founded.

After vaccinating all females in a population and preventing calving for indefinite periods the consequences on elephant behavior are unknown, as all treated populations ( $n=14$ at 2012, with 261 treated individuals) ${ }^{21}$ except GMPGR have been under PZP for less than $12 \mathrm{yr}$, and no treated population has implemented an indefinite $0 \%$ growth rate. ${ }^{10,21}$ The prevention of calving for indefinite periods can be compared to extended intercalving intervals experienced as a result of episodic natural catastrophes (e.g., drought or predation). ${ }^{28}$ Mean calving interval varies from population to population, from 2.9 to $9.1 \mathrm{yr}$, with some intervals ranging as high as $13 \mathrm{yr}{ }^{48}$ with high density populations or nutritionally stressed populations exhibiting longer intervals. ${ }^{48,49,65}$ Thus, contraception on a rotational basis or in larger populations, a predefined proportion of breeding females, will allow cohorts of births to occur, simulating natural gaps in recruitment in more natural low-resource conditions. 
The noninfluence of immunocontraception on elephant ranging behavior reflects positively on welfare consequences for elephants in the short term. While medium-term responses do not support predictions that changing resource needs as a result of fewer dependent calves leads to changes in ranging behavior, ${ }^{40}$ they impose challenges to conservationists seeking to mitigate the effects of elephants. The mechanisms of how elephants affect various conservation values associate with the intensity at which they use landscapes. ${ }^{88-90}$ Conservationists seeking to mitigate the effects of elephants will thus need to compliment population control through contraception with management interventions directed at inducing variance in elephant spatial use.

If there are concerns about overpopulation effects $^{17,30,35,39,95}$ and if immunocontraception is not chosen as the intervention with which to control populations, then some other form of population control management will have to be implemented. Other population control management interventions have not received the same scrutiny, nor have they benefited from the length of investigation presented here. Thus, longer-term effects are possible with other interventions. In order to assess options in a balanced manner, the behavioral effects of the alternative management should be assessed and the risks contrasted with those of immunocontraception..$^{12,41}$

With such comprehensive studies demonstrating that PZP contraception causes no short- to medium-term behavioral changes in elephants ${ }^{27}$ and horses, ${ }^{44,84,85}$ managers need to consider PZP immunocontraception as a realistic alternative management tool, particularly as part of a longer-term management strategy.

Acknowledgments: The authors thank the $\mathrm{Hu}-$ mane Society International for funding and support since the program's inception. Thanks are also extended to the landowners and Warden of the Greater Makalali Private Game Reserve for logistical support as well as to the Greater Makalali Private Game Reserve rangers and Siyafunda Conservation Initiative for assistance with sightings. Ms. Delsink received a National Research Foundation Bursary through National Research Foundation Grants (reference numbers: 205623 and FA2006032300024) to Robert Slotow.

\section{LITERATURE CITED}

1. Acocks, J. 1988. Veld types of South Africa. Memoirs of the Botanical Survey of South Africa, 3rd ed. Botanical Research Institute, Department of Agriculture and Water Supply, South Africa.

2. Ahlers, M., B. Ganswindt, S. Münschera, and H. Bertschinger. 2012. Fecal 20-oxo-pregnane concentrations in free-ranging African elephants (Loxodonta africana) treated with porcine zona pellucida vaccine. Theriogenology 78: 77-85.

3. Archie, E., and P. Chiyo. 2012. Elephant behaviour and conservation: social relationships, the effects of poaching, and genetic tools for management. Mol. Ecol. 21: 765-778.

4. Asa, C. 1996. Effects of contraceptives on behaviour. In: Cohn, P., E. Plotka, and U. Seal (eds.). Contraception in Wildlife. Edwin Mellon Press, Lewiston, New York. 157-190.

5. Balfour, D., H. Dublin, J. Fennessy, D. Gibson, L. Niskanen, and I. Whyte. 2007. Review of Options for Managing Impacts of Locally Overabundant African Elephants, 1st ed. The World Conservation Union (IUCN), Switzerland.

6. Balme, G., R. Slotow, and L. Hunter. 2010. Edge effects and the impact of non-protected areas in carnivore conservation: leopards in the PhindaMkhuze Complex, South Africa. Anim. Conserv. 13: 315-323.

7. Bejder, L., D. Fletcher, and S. Brager. 1998. A method for testing association patterns of social animals. Anim. Behav. 56: 719-725.

8. Benavides Valades, G., A. Ganswindt, H. Annandale, M. L. Schulman, and H. J. Bertschinger. 2012. Non-invasive assessment of the reproductive cycle in free-ranging female African elephants (Loxodonta africana) treated with a gonadotropin-releasing hormone (GnRH) vaccine for inducing anoestrus. Reprod. Biol. Endocrinol. 10: 63.

9. Bennett, D., and D. McGinnis. 2008. Coupled and complex: human-environment interaction in the Greater Yellowstone Ecosystem, USA. Geoforum 39: 833845 .

10. Bertschinger, H., A. Delsink, J. Kirkpatrick, J. van Altena, M. Ahlers, T. Dickerson, D. Powrie, and A. Burger. Porcine zona pellucida immunocontraception of African elephants (Loxodonta africana): beyond the experimental stage. In: Cain, J., 3rd, and J. Marshal (eds.). 4th International Wildlife Management Congress-Cooperative Wildlife Management Across Borders: Learning in the Face of Change. The Wildlife Society, 9-12 July 2012. Pp. 95-102.

11. Bertschinger, H., A. Delsink, J. van Altena, J. Kirkpatrick, H. Killian, A. Ganswindt, and R. Slotow. 2008. Reproductive control of elephants. In: Scholes, R., and K. Mennell (eds.). Elephant Management: A Scientific Assessment of South Africa. Wits Univ. Press, Johannesburg, South Africa. Pp. 257-328.

12. Biggs, H., R. Slotow, R. Scholes, J. Carruthers, R. van Aarde, G. Kerley, W. Twine, D. Grobler, H. Bertschinger, C. Grant, H. Lotter, J. Blignaut, L. Hopkinson, and M. Peel. 2008. Towards integrated decision making for elephant management. In: Scholes, R., and K. Mennell (eds.). Elephant Management: A 
Scientific Assessment of South Africa. Wits Univ Press, Johannesburg, South Africa. Pp. 537-586.

13. Chiyo, P. I., E. A. Archie, J. A. Hollister-Smith, P. C. Lee, J. H. Poole, C. J. Moss, and S. C. Alberts. 2011. Association patterns of African elephants in allmale groups: the role of age and genetic relatedness. Anim. Behav. 81: 1093-1099.14. Clifford, F. 2009. Wolves and the balance of nature in the Rockies. In: Smithsonian magazine. Smithsonian Institute, Washington, DC.

14. Cohen, J., and P. Cohen. 1983. Applied Multiple Regression/Correlation Analysis for the Behavioral Sciences, 2nd ed. Lawrence Erlbaum, Hillsdale, New Jersey.

15. Cowling, R., and G. Kerley. 2002. Impacts of elephants on the flora and vegetation of subtropical thicket in the Eastern Cape. In: Kerley, G., S. Wilson, and A. Massey (eds.). Elephant Conservation and Management in the Eastern Cape. University of Port Elizabeth Press, Port Elizabeth, South Africa.

16. de Beer, Y., W. Kilian, W. Versfeld, and R. van Aarde. 2006. Elephants and low rainfall alter woody vegetation in Etosha National Park, Namibia. J. Arid Environ. 64: 412-421.

17. de Iongh, H., M. Tchamba, W. Tamis, M. van't Zelde, H. Prins, H. De Haes, H. Bauer, and S. Taiwoun. 1999. Results of four years' satellite tracking of elephants in northern Cameroon. Pachyderm 27: 6265.

18. DEAT. 2008. No 251 National Environmental Management: Biodiversity Act, 2004 (Act 10 of 2004): National Norms and Standards for the Management of Elephants in South Africa DEAT (ed.). Government Gazette, Pretoria. 37.

19. Delsink, A. 2006. The costs and consequences of immunocontraception implementation in African elephants at Makalali Conservancy, South Africa. M. Sc. Thesis. Univ. of Kwa-Zulu Natal, Durban.

20. Delsink, A., and J. Kirkpatrick. 2012. Freeranging African Elephant Immunocontraception: A New Paradigm for Elephant Management. Humane Society International, Cape Town, South Africa.

21. Delsink, A., J. van Altena, D. Grobler, H. Bertschinger, J. Kirkpatrick, and R. Slotow. 2006. Regulation of a small, discrete African elephant population through immunocontraception in the Makalali Conservancy, Limpopo, South Africa. S. Afr. J. Sci. 102: 403-405.

22. Delsink, A., J. van Altena, D. Grobler, H. Bertschinger, J. Kirkpatrick, and R. Slotow. 2007. Implementing immunocontraception in African elephants at Makalali Conservancy. J. S. Afr. Vet. Assoc. 78: $25-30$.

23. Delsink, A., J. van Altena, J. Kirkpatrick, D. Grobler, and R. Fayrer-Hosken. 2002. Field applications of immunocontraception in African Elephants (Loxodonta africana). Reprod. Suppl. 60: 117-124.

24. Douglas-Hamilton, I. 1972. On the Ecology of the African Elephant. Ph.D. Dissertation. Oxford Univ., Oxford, United Kingdom.
25. Douglas-Hamilton, I. 1998. Tracking elephants with a global positioning system (GPS) radio collar. Pachyderm 25: 82-91.

26. Druce, H., R. Mackey, K. Pretorius, and R. Slotow. 2013. The intermediate-term effects of PZP immunocontraception: behavioural monitoring of the treated elephant females and associated family groups. Anim. Conserv. 16: 180-187.

27. Druce, H., R. Mackey, and R. Slotow. 2011. How immunocontraception can contribute to elephant management in small, enclosed reserves: Munyawana population as a case study. PLoS ONE. 6(12):e27952. doi: 10.1371/journal.pone.0027952.

28. Druce, H., K. Pretorius, and R. Slotow. 2008. The response of an elephant population to conservation area expansion: Phinda Private Game Reserve, South Africa. Biol. Conserv. 141: 3127-3138.

29. Duffy, K., J. van Os, R. van Aarde, G. Ellish, and A. Stretch. 2002. Estimating impact of reintroduced elephant on trees in a small reserve. S. Afr. J. Wildl. Reserve 32: 23-29.

30. Estes, R. 1991. The behaviour guide to African mammals. Russel Friedman Books, South Africa.

31. Fayrer-Hosken, R., D. Grobler, J. van Altena, H. Bertschinger, and J. Kirkpatrick. 2000. Immunocontraception of African elephants. Nature 407: 149.

32. Garai, M. 1997. The development of social behaviour in translocated juvenile elephants. Univ. of Pretoria, Pretoria.

33. Ginsberg, J., and T. Young. 1992. Measuring association between individuals or groups in behavioural studies. Anim. Behav. 44: 377-379.

34. Grainger, M., R. van Aarde, and I. Whyte. 2005. Landscape heterogeneity and the use of space by elephants in the Kruger National Park, South Africa. Afr. J. Ecol. 43: 369-375.

35. Hooge, P., and B. Eichenlaub. 1997. Animal Movement Extension to Arcview. Alaska Biological Science Centre, U.S. Geological Survey, Anchorage, Alaska.

36. Hopkinson, L., M. Van Staden, and J. Ridl. 2008. National and international law. In: Mennell, K., and R. Scholes (eds.). Elephant Management: A Scientific Assessment of South Africa. Wits Univ. Press, Johannesburg, South Africa. Pp. 477-536.

37. Jachowski, D., R. Slotow, and J. Millspaugh. 2012. Physiological stress and refuge behavior by African elephants. PLoS ONE 7: e31818.

38. Kerley, G., M. Landman, L. Kruger, N. OwenSmith, D. Balfour, W. de Boer, A. Gaylard, K. Lindsay, and R. Slotow. 2008. Effects of elephants on ecosystems and biodiversity. In: Mennell, K., and R. Scholes (eds.). Elephant Management: A Scientific Assessment of South Africa. Wits Univ. Press, Johannesburg, South Africa. Pp. 146-206.

39. Kerley, G., and A. Shrader. 2007. Elephant contraception: silver bullet or a potentially bitter pill? S. Afr. J. Sci. 103:181-182.

40. Kirkpatrick, J. 2007. Measuring the effects of wildlife contraception: the argument for comparing apples with oranges. Reprod. Fertil. Dev. 19: 548-552. 
41. Kirkpatrick, J. 2012. Immunocontraceptive Reproductive Control Utilizing Porcine Zona Pellucida (PZP) in Federal Wild Horse populations, 4th ed. Science and Conservation Center, Billings, Montana.

42. Kirkpatrick, J., R. Lyda, and K. Frank. 2011. Contraceptive vaccines for wildlife; a review. Am. J. Reprod. Immunol. 66: 40-50.

43. Kirkpatrick, J., and A. Turner. 2008. Achieving population goals in a long-lived wildlife species (Equus caballus) with contraception. Wildl. Res. 35: 513-519.

44. Kirkpatrick, J., and J. Turner. 1996. Fertility control in wildlife management: a review. In: Cohn, P., E. Plotka, and U. Seal (eds.). Contraception in Wildlife. Blackwell Scientific Publications, North America. Pp. 133-155.

45. Knight, M. 2011. African Rhino Specialist Group report. 10th Meeting of the IUCN/SCC African Rhino Specialist Group. Pachyderm 49: 6-15.

46. Laws, R. 1966. Age criteria for the African elephant Loxodonta a. africana. East Afr. Wildl. J. 4: 1-37.

47. Laws, R. 1969. Aspects of reproduction in the African elephant Loxodonta africana. J. Reprod. Fertil. Suppl. 6: 193-217.

48. Laws, R., I. Parker, and R. Johnstone. 1975. Elephants and their Habitats: The Ecology of Elephants in North Bunyoro, Uganda. Clarendon Press, Oxford, United Kingdom.

49. Loarie, S., R. van Aarde, and S. Pimm. 2009. Fences and artificial water affect African savannah elephant movement patterns. Biol. Conserv. 142: 30863098 .

50. Lyda, R., R. Hall, and J. Kirkpatrick. 2005. A comparison of Freund's complete and Freund's modified adjuvants used with a contraceptive vaccine in wild horses. J. Zoo Wildl. Med. 36: 610-616.

51. Mackey, R., B. Page, D. Duffy, and R. Slotow. 2006. Modelling elephant population growth in small, fenced, South Africa reserves. S. Afr. J. Wildl. Manag. 36: 33-43.

52. Morgan, S., R. Mackey, and R. Slotow. 2009. A priori valuation of land use for the conservation of black rhinoceros (Diceros bicornis). Biol. Conserv. 142: 384-393.

53. Moss, C. 1983. Oestrous behaviour and female choice in the African elephant. Behaviour 86: 167-196.

54. Moss, C. 1996. Getting to know a population. In: Kangwana, K. (ed.). Studying Elephants. African Wildlife Foundation, Kenya. Pp. 58-74.

55. Moss, C., and J. Poole. 1983. Relationships and social structure of African elephants. In: Hinde, R. (ed.). Primate Social Relations: An Integrated Approach. Sinauer, New York, New York. Pp. 315-325.

56. O'Connell, C. 2008. The Elephant's Secret Sense. Univ. of Chicago Press, Chicago, Illinois.

57. O'Connell-Rodwell, C. 2010. How male elephants bond. In: Smithsonian Magazine. Smithsonian Institute, Washington, DC.

58. Perdock, A., W. de Boer, and T. Stout. 2007. Prospects for managing African elephant population growth by immunocontraception: a review. Pachyderm 42: 92-107.

59. Pinter-Wollman, N. 2012. Human-elephant conflict in Africa: the legal and political viability of translocations, wildlife corridors, and transfrontier parks for large mammal conservation. J. Int. Wildl. Law Policy 15: 152-166.

60. Poole, J. 1982. Musth and male-male competition in the African elephant. Cambridge Univ, Press, Cambridge, United Kingdom.

61. Poole, J. 1987. Rutting behaviour in African elephants: the phenomenon of musth. Behaviour 102: 283-316.

62. Poole, J. 1989. Announcing intent: the aggressive state of musth in African elephants. Anim. Behav. 37: 140-152.

63. Poole, J. 1989. Mate guarding, reproductive success and female choice in African elephants. Anim. Behav. 37: 842-849.

64. Poole, J. 1996. The African elephant. In: Kangwana, K. (ed.). Studying Elephants. African Wildlife Foundation, Kenya. Pp. 1-8.

65. Poole, J., and C. Moss. 1981. Musth in the African elephant. Nature 292: 830-831.

66. Rabinowitz, A. 2005. Jaguars and livestock: living with the world's third largest cat. In: Woodroffe, R., S. Thirgood, and A. Rabinowitz (eds.). People and Wildlife: Conflict or Co-Existence? Cambridge Univ. Press, Cambridge, United Kingdom. Pp. 278-286.

67. Ripple, W., and R. Beschta. 2006. Linking a cougar decline, trophic cascade, and catastrophic regime shift in Zion National Park. Biol. Conserv. 133: 397-408.

68. Ripple, W., and R. Beschta. 2007. Restoring Yellowstone's aspen with wolves. Biol. Conserv. 138: 514-519.

69. Ripple, W., E. Larsen, R. Renkin, and D. Smith. 2001. Trophic cascades among wolves, elk and aspen on Yellowstone National Park's northern range. Biol. Conserv. 102: 227-234.

70. SANParks. 2009/2010. Annual Report. SANParks, Pretoria.

71. SANParks. 2011. Standard Operating Procedures for the Capture, Transportation and Maintenance in Holding Facilities of Wildlife: Elephant. SANParks, Veterinary Wildlife Services, Skukuza.

72. Seaman, D., J. Millspaugh, B. Kernohan, K. Brundige, K. Raedeke, and R. Gitzen. 1999. Effects of sample size on kernel home range estimates. J. Wildl. Manag. 63: 739-747.

73. Slotow, R., and G. van Dyk. 2004. Ranging of older male elephants introduced to an existing small population without older males: Pilanesberg National Park. Koedoe 47: 91-104.

74. Slotow, R., I. Whyte, M. Hofmeyr, G. Kerley, T. Conway, and R. Scholes. 2008. Lethal management of elephant. In: Scholes, R., and K. Mennell (eds.). Elephant Management: A Scientific Assessment of South Africa. Wits Univ. Press, Johannesburg, South Africa. Pp. 370-405. 
75. Smit, I., C. Grant, and B. Devereux. 2007. Do artificial waterholes influence the way herbivores use the landscape? Herbivore distribution patterns around rivers and artificial surface water sources in a large African savanna park. Biol. Conserv. 136: 85-99.

76. Smit, I., C. Grant, and I. Whyte. 2000. Elephants and water provision: what are the management links? Divers. Distrib. 13: 666-669.

77. Spenceley, A. 2005. Nature-based tourism and environmental sustainability in South Africa. J. Sustainable Tourism 13: 136-170.

78. Stout, T., and B. Colenbrander. 2004. Contraception as a tool for limiting elephant population growth: the possible pitfalls of various approaches. In: de Gooijer, J., and R. Paling (eds.). Proceedings of the 15th Symposium on Tropical Animal Health and Reproduction: Management of Elephant Reproduction. Utrecht Univ., Utrecht, The Netherlands. Pp. 711.

79. Swihart, R., and N. Slade. 1985. Testing for independence of observations in animal movements. Ecology 66: 1176-1184.

80. Thirgood, S., R. Woodroffe, and A. Rabinowitz. 2005. The impact of human-wildlife conflict on human lives and livelihoods. In: Woodroffe, R., S. Thirgood, and A. Rabinowitz (eds.). People and Wildlife: Conflict or Co-Existence? Cambridge Univ. Press, Cambridge, United Kingdom. Pp. 13-26.

81. Thouless, C. 1996. Satellite tracking of elephants. In: Kangwana, K. (ed.). Studying Elephants. African Wildlife Foundation, Kenya. Pp. 120-125.

82. Turnbull, P., R. Bell, F. Saigawa, F. Munyenyembe, C. Mulenga, and L. Makala. 1991. Anthrax in wildlife in the Luangwa Valley, Zambia. Vet. Rec. 128: 399-403.

83. Turner, J., and J. Kirkpatrick. 2002. Effects of immunocontraception on population, longevity and body condition in wild mares (Equus caballus). Reprod. Suppl. 60: 187-195.

84. Turner, J., I. Liu, D. Flanagan, K. Bynum, and A. Rutberg. 2002. Porcine zona pellucida (pZP) immunocontraception of wild horses (Equus caballus) in Nevada: a 10 year study. Reprod. Suppl. 60: 177-186.

85. Twine, W., and H. Magome. 2008. Interactions between elephants and people. In: Mennell, K., and R. Scholes (eds.). Elephant Management: A Scientific Assessment of South Africa. Wits Univ. Press, Johannesburg, South Africa. Pp. 206-240.

86. van Aarde, R., S. Ferreira, T. Jackson, B. Page, Y. de Beer, K. Gough, R. Guldemond, J. Junker, P. Olivier, T. Ott, and M. Trimble. 2008. Elephant population biology and ecology. In: Scholes, R., and K. Mennell (eds.). Elephant Management: A Scientific Assessment for South Africa. Wits Univ. Press, Johannesburg, South Africa. Pp. 84-115.

87. van Aarde, R., and T. Jackson. 2007. Megaparks for metapopulations: addressing the causes of locally high elephant numbers in southern Africa. Biol. Conserv. 134: 289-297.

88. van Aarde, R., T. Jackson, and S. Ferreira. 2006. Conservation science and elephant management in southern Africa. S. Afr. J. Sci. 102: 385-388.

89. Vanak, A., M. Thaker, and R. Slotow. 2010. Do fences create an edge-effect on the movement patterns of a highly mobile mega-herbivore? Biol. Conserv. 143: 2631-2637.

90. Walpole, M., and N. Leader-Williams. 2002. Ecotourism and flagship species in conservation. Biodivers. Conserv. 11: 543-547.

91. Wasser, S., W. Clark, and C. Laurie. 2009. The ivory trail. Sci. Am. 301: 68-76.

92. Whitehouse, A., and G. Kerley. 2002. Retrospective assessment of long-term conservation management of elephants in Addo Elephant National Park, South Africa. Oryx 36: 243-248.

93. Whyte, I. 2001. Conservation Management of the Kruger National Park Elephant Population. Univ. of Pretoria, Pretoria.

94. Whyte, I., R. van Aarde, and S. Pimm. 2003. Kruger's elephant population: its size and consequences for ecosystem heterogeneity. In: du Toit, J., K. Rogers, and H. Biggs (eds.). The Kruger Experience: Ecology and Management of Savanna Heterogeneity. Island Press, Washington. Pp. 332-348.

95. Wittemyer, G., I. Douglas-Hamilton, and W. Getz. 2005. The socioecology of elephants: analysis of the processes creating multitiered social structures. Anim. Behav. 69: 1357-1371.

96. Wittemyer, G., and W. Getz. 2007. Hierarchical dominance structure and social organization in African elephants, Loxodonta africana. Anim. Behav. 73: 671681.

97. Woolley, L., J. Millspaugh, R. Woods, S. Janse van Rensburg, R. Mackey, B. Page, and R. Slotow. 2008. Population and individual elephant response to a catastrophic fire in Pilanesberg National Park. PLoS ONE 3(9):e3233. doi:10.1371/journal.pone.0003233.

98. Worton, B. 1989. Kernel methods for estimating the utilization distribution in home-range studies. Ecology 70: 164-168.

99. Wright, J., and C. Jones. 2006. The concept of organisms as ecosystem engineers ten years on: progress, limitations and challenges. BioScience 56: 203209.

100. Young, T., T. Palmer, and M. Gadd. 2005. Competition and compensation among cattle, zebras and elephants in a semi-arid savanna in Laikipia, Kenya. Biol. Conserv. 122: 251-259.

101. Zar, J. 1999. Biostatistical Analysis, 4th ed. Prentice Hall, New Jersey.

Received for publication 20 September 2012 